Report No. BMI-1315

UC-25 Metallurgy and Ceramics (TID-4500, 14th Ed.)

Contract No. W-7405-eng-92

PROGRESS RELATING TO CIVILIAN APPLICATIONS

DURING JANUARY, 1959

by

Russell W. Dayton

Clyde R. Tipton, Jr.

February 1, 1959

Declassified June 12, 1959

BATTELLE MEMORIAL INSTITUTE 505 King Avenue

Columbus 1, Ohio 


\section{DISCLAIMER}

This report was prepared as an account of work sponsored by an agency of the United States Government. Neither the United States Government nor any agency Thereof, nor any of their employees, makes any warranty, express or implied, or assumes any legal liability or responsibility for the accuracy, completeness, or usefulness of any information, apparatus, product, or process disclosed, or represents that its use would not infringe privately owned rights. Reference herein to any specific commercial product, process, or service by trade name, trademark, manufacturer, or otherwise does not necessarily constitute or imply its endorsement, recommendation, or favoring by the United States Government or any agency thereof. The views and opinions of authors expressed herein do not necessarily state or reflect those of the United States Government or any agency thereof. 


\section{DISCLAIMER}

Portions of this document may be illegible in electronic image products. Images are produced from the best available original document. 


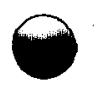




\section{TABLE OF CONTENTS}

ZEPOR TS RELATING TO CIVILIAN APPLICATIONS ISSUED DURING JANUARY, 1959 . . . . . . . . . 5

A. ASSISTANCE TO HAPO . . . . . . . . . . . . . . . . . . . . . . . . . . . . . . . . 7

Thermal Conductivity of $\mathrm{U}_{\mathrm{ranium}}$ and $\mathrm{UO}_{2}$.

Mechanical Properties of Zirconium Alloys . . . . . . . . . . . . . . . . . . . 10

Preparation of Molybdenum Single Crystals . . . . . . . . . . . . . . . . . . . . 10

Physical Distortion of Graphite . . . . . . . . . . . . . . . . . . . . . . . . . . . . . . $\quad .10$

Evaluation of Possible Loss-of-Coolant Incidents in the Plutonium Recycle Test Reactor . . . 11

3. DEVELOPMENTS FOR ALUMINUM-CLAD FUEL ELEMENTS . . . . . . . . . . . . . . . . 15

Preparation of Aluminum-Uranium Alloys . . . . . . . . . . . . . . . . . . . 15

c. RADIOISOTOPE AND RADIATION APPLICATIONS . . . . . . . . . . . . . . . . . . . . . . . 17

Development of Radioactive-Tracer Quality-Cortrol Systems . . . . . . . . . . . . . 17

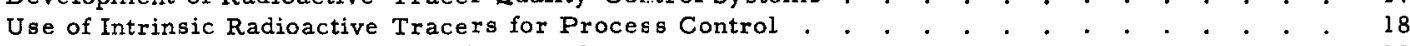

Radiation Chemistry of Inclusion Compounds . . . . . . . . . . . . . . . . . $\quad 18$

1). PROCESSING OF FEED MATERLALS. . . . . . . . . . . . . . . . . . . . . . . . . . . . . . . . 21

Solidification of Uranium . . . . . . . . . . . . . . . . . . . . . . . . . 21

J. SPRAY DEPOSITION OF CALCIUM METAL ON NICKEL, OR INCONEL . . . . . . . . . . . . . . 23

1i. RESEARCH FOR AEC REACTOR DEVELOPMENT DIVISION PROGRAM . . . . . . . . . . . . 25

REACTOR MATERIALS AND COMPONENTS . . . . . . . . . . . . . . . . . . . . 25

Valence Effects of Oxide Additions to Uranium Lioxide . . . . . . . . . . . . . . . . . . 26

High-Pressure High-Temperature Solid-State Studies . . . . . . . . . . . . . . . 27

Fueled Zirconium Hydride Moderator . . . . . . . . . . . . . . . . . . . . . . . . . . . . . . . 28

Irradiation Surveillance Program on Type 347 St:ainless Steel . . . . . . . . . . . . . 29

STUDIES OF ALLOY FUELS . . . . . . . . . . . . . . . . . . . . . . . . . . . 30

Development of Niobium-Base Alloys . . . . . . . . . . . . . . . . . . . . . 31

Development of Niobium-Uranium Alloys . . . . . . . . . . . . . . . . . . . 31

Development of Thorium-Uranium Alloys . . . . . . . . . . . . . . . . . . . . . . . 34

FISSION-GAS RELEASE FROM REFRACTORY FUELS . . . . . . . . . . . . . . . . . 35

GENERAL FUEL-ELEMENT DEVELOPMENT . . . . . . . . . . . . . . . . . . . . . 36

Fabrication of Cermet Fuel Elements . . . . . . . . . . . . . . . . . . . . . 36

Gas-Pressure Bonding of Molybdenum- and Niobium-Clad Fuel Elements . . . . . . . . . 37

The Irradiation of UC- and UN-Stainless Steel Dispersion-Type Fuel Elements . . . . . . . . . 39

Factors Affecting Pressure Bonding . . . . . . . . . . . . . . . . . . . . . . 40

C. FATIGUE STUDIES OF INCONEL AND INOR-8 . . . . . . . . . . . . . . . . . . . . . . . . . . . . . . 41

Fatigue Studies of Incone1 . . . . . . . . . . . . . . . . . . . . . . . . . . . . . . 41

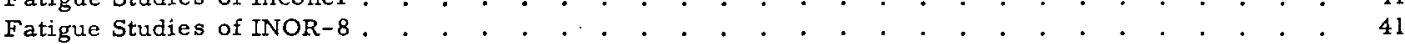

F. PHYSICAL RESEARCH . . . . . . . . . . . . . . . . . . . . . . . . . . . . 43

Preparation and Properties of Refractory Uranium Compounds . . . . . . . . . . . . . . . 43

The rmal Migration of Hydrogen in Zirconium . . . . . . . . . . . . . . . . . . . . . . . . . . . . . . . 
I. SOLID HOMOGENEOUS FUELED REACTORS . . . . . . . . . . . . . . . . . . . . . . . . 47

Postirradiation Evaluation of Spherical Fueled-Graphite Specimens . . . . . . . . . . . 47

Encapsulation and Irradiation . . . . . . . . . . . . . . . . . . . . . . . . . . . 52

Measurements of Fission-Gas Release During Postirradiation Heating of Fueled-Graphite Balls $\cdot \dot{b}^{\cdot} \quad 54$

J. CORROSION PROBLEMS ASSOCIATED WITH THE RECOVERY OF SPENT REACTOR FUEL ELEMENTS . 57

The Darex Process. . . . . . . . . . . . . . . . . . . . . . . . . . . 57

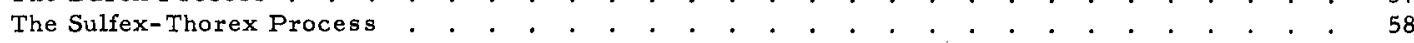

The Zirflex Process . . . . . . . . . . . . . . . . . . . . . . . . . . . 59

The Fluoride-Volatility Process . . . . . . . . . . . . . . . . . . . . . . 59

K. DEVELOPMENTS FOR SRE, OMRE, AND OMR . . . . . . . . . . . . . . . . . . . . . . . . 61

EVALUATION OF URANIUM MONOCARBIDE AS A REACTOR FUEL . . . . . . . . . . . . . . 61

Irradiation of Uranium Monocarbide . . . . . . . . . . . . . . . . . . . . . 61

Postirradiation Examination of Uranium Monocarbide . . . . . . . . . . . . . . . 62

POSTIRRADIATION STUDIES OF SRE, OMRE, AND OMR FUEL MATERIALS . . . . . . . . . . 62

OMR Fuel Plates. . . . . . . . . . . . . . . . . . . . . . . . . . . 62

OMRE Fuel Elements . . . . . . . . . . . . . . . . . . . . . . . . . . . . . . 63

SRE Fuel Materials . . . . . . . . . . . . . . . . . . . . . . . . . . . 63

L. TANTALUM AND TANTALUM-ALloY StUdieS . . . . . . . . . . . . . . . . . . . . . . 67

Development of Container Materials for LAMPRE Applications . . . . . . . . . . . . . . 67

Irradiation Damage of Tantalum . . . . . . . . . . . . . . . . . . . . . . . . . . . . . . . 69

M. DEVELOPMENTAL STUDIES FOR THE PWR . . . . . . . . . . . . . . . . . . . . . . . . . . 71

Reactor Flow Studies . . . . . . . . . . . . . . . . . . . . . . . . . . . . 71

Pressure Bonding of Zircaloy-2-Clad Fuel Elements Containing Compartmented Oxide

Fuel Plates. . . . . . . . . . . . . . . . . . . . . . . . . . . . . 71

N. DEVELOPMENTS FOR THE MGCR . . . . . . . . . . . . . . . . . . . . . . . . . . . . . 75

THE POSTIRRADIATION EXAMINATION OF GA-BNL SINTERED UO 2 FUEL SPECIMENS

CLAD WITH STAINLESS STEEL . . . . . . . . . . . . . . . . . . . . . . . . . . . 75

FABRICATION AND IRRADIATION OF FUEL MATERIALS . . . . . . . . . . . . . . . . . . 76

Fabrication of BeO-UO $\mathrm{UO}_{2}$ Fuel Elements . . . . . . . . . . . . . . . . . . . . 76

Fabrication of Graphite Fuel Elements . . . . . . . . . . . . . . . . . . . . . . . . . . 77

Radiation-Effects Study of Potential Fuels

CORE-MATERIALS IRRADIATION PROGRAM . . . . . . . . . . . . . . . . . . . . . . . . 78

O. ENGINEERING ASSISTANCE TO KAISER ENGINEERS . . . . . . . . . . . . . . . . . . . . . . . 81

Reactor Flow Studies . . . . . . . . . . . . . . . . . . . . . . . . . 81

P. DEVELOPMENTAL STUDIES FOR THE APPR . . . . . . . . . . . . . . . . . . . . . . . . . . . 83

Encapsulation Studies . . . . . . . . . . . . . . . . . . . . . . . . . . 83

Development of Fuel Materials . . . . . . . . . . . . . . . . . . . . . . $\quad . \quad 84$ 


\title{
5 and 6
}

REPORTS RELATING TO CIIVILIAN APPLICATIONS

ISSUED DURING JANUARY, 1959

\begin{abstract}
BMI-1307 "Progress Relating to Civilian Applications During December, 1958", by Russell W. Dayton and Clyde R. Tipton, Jr.

BMI-1309 "Preparation and Properties of Uranium Monocarbide Castings", by Arthur C. Secrest, Jr., Ellis L. Foster, and Ronald F. Dickerson.

BMI-1310 "Prototype Gages to Measure Plate Spacing in Flat Fuel-Plate Subassemblies", by Neil E. Miller, C. Vernon Weaver, and William H. Goldthwaite.
\end{abstract}


$A-1$

\section{A. ASSISTANCE TO HAPO}

F. R. Shober

Thermal-conductivity measurements are being made on unirradiated uranium and $\mathrm{UO}_{2}$ to obtain base values for comparison with those to be obtained on irradiated specimers of these materials. Values for four specimens of unirradiated $\mathrm{UO}_{2}$ are reported. The creep properties of 15 per cent cold-worked Zircaloy-2 are being evaluated in the 290 to $400 \mathrm{C}$ temperature range. Cyclic-temperature test conditions increase the creep rates over those of constant-temperature tests.

A new lot of molybdenum has been received and preparation of single crystals has beer resumed. The density distribution of crushed graphite is being investigated by the sink-float technique. Measurements indicate that the experimental method is yielding reproducible results. Samples of various density are to be prepared for irradiation.

A program has been initiated to evaluate possible loss-of-coolant incidents in the Plutonium Recycle Test Reactor (PRTR) by means of simulation on a digital computer. The program is to include computing temperature excursions of the fuel element after incilents and calculations of the extent of metal-steam reaction for a short period after the incident.

\section{Thermal Conductivity of Uranium and $\mathrm{UO}_{2}$}

H. W. Deem and C. F. Lucks

Uranium

Thermal-conductivity measurements ale in progress on an unirradiated, unclad, natural uranium specimen. The specimen is a right cylinder about $1 / 2$ in. in diameter and 5-5/8 in. long. The unirradiated specimens are of the same stock as the irradiated specimens to be measured.

The apparatus and method being used in making the thermal-conductivity measurernents are essentially the same as the steady-heat-flow method described by Van Dusen and Shelton. * The method, in brief, consists in heating one end of a specimen, measuring the temperature gradients along the specimen, and determining the rate of heat flow through the specimen by means of a metal standard of known thermal conductivity attached to the cold end of the specimen. Radial heat flow into, or away from, the specimen is minimized by radiation shielding and an encircling guard tube in which temperatures are adjusted, as nearly as possible, to match those in the specimen and standard at corresponding levels. The radiation shielding used consists of small pellets rolled from fractional-mil-thicle tantalum foil, poured into the annular space between the specimen assembly and the guard cylinder. The specimen is protected by a vacuum of approximately $2 \times 10^{-5} \mathrm{~mm}$ of mercury during the measurements.

- Var Dusen, M. S. and Shelton, S. M., "Apparatus for Measuring Thermal Conductivity of Metals up to $600 \mathrm{C}$ ", Nat. Bur. Staildards, J. Research, 12, 429-440 (1934). 


$$
\mathrm{A}-2
$$

Five 36-gage Chromel-Alumel thermocouples are wedged in holes equally spaced along the specimen, and two similar thermocouples are placed in the Armco-iron standard. This permits the calculation of four thermal-conductivity values, each at a different mean temperature, for each thermal equilibrium.

Tin was used to join the specimen to the heater block on one end and to the Armco iron standard on the other end. Ends of the uranium specimen were electroplated with nickel and then tinned with a soldering iron.

Table A-1 shows tentative thermal conductivity for the uranium specimen measured. The data are based on the thermal equilibria obtained to date and are subject to change with subsequent equilibria. The values in Table A-1 agree very closely with values for other natural uranium as previously reported in BMI-I 267. If subsequent thermal equilibria do not significantly change the values shown in Table A-1, they will be used as the basis for measuring the effect of irradiation of the thermal conductivity of uranium.

TABLE A-1. TENTATIVE THERMAL-CONDUCTIVITY VALUES OF UNIRRADIATED NATURAL URANIUM

\begin{tabular}{cc}
\hline Temperature, C & $\begin{array}{c}\text { Thermal Conductivity, } \\
\text { w/(cm)(C) }\end{array}$ \\
\hline 20 & 2.40 \\
100 & 2.55 \\
200 & 2.75 \\
300 & 3.02 \\
400 & 3.28 \\
500 & 3.55 \\
600 & 3.90 \\
700 & 4.25 \\
\hline
\end{tabular}

During February, preparations for making thermal-conductivity measurements on irradiated uranium will be started.

\section{Uranium Oxide}

The apparatus used in measuring the thermal conductivity of $\mathrm{UO}_{2}$ was described in $\mathrm{BMI}-1301$.

During January, measurements were started on Specimen 68, a medium-density (91.9 per cent of theoretical) $\mathrm{UO}_{2}$ sample. Measurements are still continuing to be made. Table A -2 shows tentative interpolated thermal-conductivity values based on the thermal equilibria to date. These values are subject to change as additional equilibria are obtained. Values adjusted to 100 per cent of theoretical density are shown. 


$$
A-3
$$

TABLE A-2. TENTATIVE THERMAL-CONDUCTIVITY VALUES FOR $\mathrm{UO}_{2}$ SPECIMEN 68

Specimen density is 91.9 per cent of theoretical.

\begin{tabular}{ccc}
\hline & & \multicolumn{2}{c}{$\begin{array}{c}\text { Thermal Conductivity, } \\
\text { Temperature, } C\end{array}$} & $\frac{\mathrm{w}(\mathrm{cm})(\mathrm{C})}{\mathrm{d}=91.9(\mathrm{a})}$ & $\mathrm{d}=100(\mathrm{~b})$ \\
\hline 100 & 0.073 & 0.079 \\
200 & 0.058 & 0.063 \\
300 & 0.049 & 0.053 \\
400 & 0.042 & 0.046 \\
500 & 0.037 & 0.040 \\
\hline
\end{tabular}

(a) $\mathrm{d}=$ per cent of theoretical density.

(b) Thermal conductivity adjusted to 100 per cent of theoretical density by linear extrapolation.

Table A-3 gives identification data on the four specimens measured to date. Table A-4 gives interpolated thermal-conductivity values at selected temperatures for the three specimens for which measurements have been completed.

During February, measurements on Specimen 68 will be completed and work will begin on setting up the apparatus at the hot cell.

TABLE A-3. URANIUM OXIDE DENSITY DATA

\begin{tabular}{cccccc}
\hline Specimen & Mass, g & Diameter, in. & Length, in. & Density, g/cm2 & $\begin{array}{c}\text { Density, } \\
\text { per cent } \\
\text { theoretical }\end{array}$ \\
\hline 1000 & 25.2492 & 0.248 & 3.120 & 10.27 & 93.7 \\
70 & 25.3475 & 0.251 & 3.015 & 10.45 & 9.58 \\
65 & 23.1172 & 0.249 & 3.033 & 10.07 & 87.4 \\
68 & 24.2611 & 0.250 & 3.001 & 91.9 \\
\hline
\end{tabular}

TABLE A -4. INTERPOLATED THERMAL CONDUCTIVITY OF $\mathrm{UO}_{2}$ OF VARIOUS DENSITIES

\begin{tabular}{|c|c|c|c|c|c|c|}
\hline \multirow[b]{3}{*}{ Temperature, $C$} & \multicolumn{6}{|c|}{ Thermal Conductivity, $w /(\mathrm{cm})(\mathrm{C})$} \\
\hline & \multicolumn{2}{|c|}{ Specimen 1000 (a) } & \multicolumn{2}{|c|}{ Specimen 70} & \multicolumn{2}{|c|}{ Specimen 65} \\
\hline & $d=93.7(b)$ & $\mathrm{d}=100(\mathrm{c})$ & $\mathrm{d}=95.3^{(b)}$ & $d=100(c)$ & $\mathrm{d}=87.4(\mathrm{~b})$ & $\mathrm{d}=100(\mathrm{c})$ \\
\hline 100 & 0.0789 & 0.0842 & 0.0754 & 0.0791 & 0.0672 & 0.0769 \\
\hline 200 & 0.0652 & 0.0696 & 0.0610 & 0.0640 & 0.0556 & 0.0636 \\
\hline 300 & 0.0556 & 0.0593 & 0.0513 & 0.0538 & 0.0473 & 0.0541 \\
\hline 400 & 0.0485 & 0.0517 & 0.0442 & 0.0464 & 0.0412 & 0.0471 \\
\hline 500 & 0.0429 & 0.0458 & 0.0389 & 0.0408 & 0.0365 & 0.0418 \\
\hline 600 & 0.0385 & 0.0411 & 0.0347 & 0.0364 & 0.0328 & 0.0375 \\
\hline 700 &.- & - & 0.0313 & 0.0328 & 0.0297 & 0.0340 \\
\hline 800 & -- & $\ldots$ & 0.0285 & 0.0299 & 0.0272 & 0.0311 \\
\hline
\end{tabular}

a) Different fabrication method used in preparation of Specimen 1000 than of others. Details not known at this time.

ib) $\mathrm{d}=$ per cent of theoretical density.

(c) Thermal conductivity adjusted to 100 per cent of theoretical density by linear extrapolation. 
Mechanical Properties of Zirconium Alloys

F. R. Shober and J. A. VanEcho

The creep properties of annealed and of 15 per cent cold-worked Zircaloy-2 are being studied. The program includes creep tests both at constant temperature and under cyclic-temperature conditions over the range 290 to $400 \mathrm{C}$. The constanttemperature tests are long-time creep tests on cold-worked material. It is expected that most tests will continue for times greater than $10,000 \mathrm{hr}$.

It is expected that 20 vacuum creep units will be in operation by mid-February. The deformations associated with cyclic-temperature tests appear to be slightly greater for the same stresses than those observed in the constant-temperature tests. Annealed. Zircaloy-2 will be tested under cyclic-temperature conditions also.

\section{Preparation of Molybdenum Single Crystals}

J. A. DeMastry, F. R. Shober, and R. F. Dickerson

Additional molybdenum rod has been received and preparation of single crystals of molybdenum is being resumed. Six crystals have been grown to date, and six more will be grown to complete this phase of the work.

After completion of the molybdenum single crystals, attempts will be made to prepare single crystals of alpha zirconium. Two slightly different heat-treating schedules will be used on solid rods in the Andrade furnace. One heat-treatment schedule will consist of annealing in the high-beta region, $1700 \mathrm{C}$, followed by an anneal at $850 \mathrm{C}$ or high-alpha region. Times at these temperatures will need to be determined. The second heat treatment will be in the high-alpha range $850 \mathrm{C}$ for 8 to $10 \mathrm{hr}$. A dynamic vacuum having a pressure of $10^{-5} \mathrm{~mm}$ of mercury will be necessary for this study.

\section{Physical Distortion of Graphite}

J. Koretzky, W. C. Riley, and W. H. Duckworth

11

Research to develop a method of sink-float density measurements to identify factors affecting radiation-induced volume changes in graphite was continued.

Coarse-porosity fritted-glass filters were substituted for the medium-porosity filters previously used. The porosity of the coarse filter was fine enough to remove all the graphite from the filtrate. The use of a coarser filter reduced the time required to separate the graphite from the benzene-bromoform solution, thereby reducing the error in specific gravity due to evaporation of small quantities of benzene. $/ 2$ 


\section{A -5}

:'y Measurements of the sink-float density distribution of one sample each of minus 140 Jlus $170-$, minus 170 plus $200-$, and minus 200 plus $270-$ mesh TS-GBF graphite were: made. $/ 3$ The results are in close agreement and are summarized in Table A -5 .

3/The density distributions of two specimens of a composite of minus 270 plus 325mesia and minus 325-mesh TS-GBF graphite from Sample 127-96 were measured. Neally identical density distributions were obtained, indicating good reproducibility in the experimental method. The results were compared with the density distributions of indiridual specimens of minus 270 plus 325 -mesh and minus 325-mesh TS-GBF graphite from Sample 127-33. The composite sample contained less low-density material than the uninus 325-mesh specimen and more low-density material than the minus 270 plus 325-mesh specimen./ 4 The results are summarized in Table A-6.5/The results from thes s samples indicate that Sample 127 may be uniform with respect to sink-float density distribution. Jend

The density distributions of composite samples of minus 40 plus $140-$, minus 140 plus 270-, and minus 40 plus 270-mesh material from Sample 127-96 will be measured. The results will be compared with the density distributions of specimens from Sample 127-33. Samples of various density fractions will be prepared for irradiation.

\section{Evaluation of Possible Loss-of-Coolant Incidents} in the Plutonium Recy cle Test Reactor

C. A. Alexander, L. E. Hulbert, A. W. Lemmon, Jr., and R. B. Filbert, Jr.

A program was initiated this month to evaluate possible loss-of-coolant incidents in the Plutonium Recycle Test Reactor (PRTR) by means of simulation on a digital computer.

The PRTR is a thermal heterogeneous test reactor in which both $\mathrm{UO}_{2}$ and plutoniur. will be employed as fuels. A preliminary analysis indicated that the most probable severe incidents in the PRTR are those which do not entail nuclear excursions but involvi a break in the primary coolant system with simultaneous failure of the light-water backup cooling system.

The breaks to be considered are: a double 14-in. top break, a single 14-in. top break, a double 1-1/2-in. top break, and a double 1-1/2-in. bottom break. A double break indicates that the pipe is sheared off and displaced so that discharge can come frorn both ends, while a single break refers to a hole in a pipe of this equivalent diarzeter.

The program will include computing temperature excursions of the fuel elements afte $r$ the incidents until the melting point is reached, and also calculating the extent of metal-steam reaction for a period of several minutes after the incident. Provisions have been made to consider the effect of addition of emergency cooling water at different times after the incident. 
TABLE A-5. DENSITY DISTRIBUTION OF MINUS 140 PLUS 170-, MINUS 170 PLUS 200-, AND MINUS 200 PLUS 270-MESH TS-GBF GRAPHITE

From Sample 127-33.

\begin{tabular}{|c|c|c|c|c|c|c|c|c|}
\hline \multicolumn{3}{|c|}{ Minus 140 Plus 170 Mesh } & \multicolumn{3}{|c|}{ Minus 170 Plus 200 Mesh } & \multicolumn{3}{|c|}{ Minus 200 Plus $270 \mathrm{Mesh}$} \\
\hline $\begin{array}{c}\text { Specific Gravity of } \\
\text { Benzene-Bromoform } \\
\text { Solution }\end{array}$ & $\begin{array}{l}\text { Amount } \\
\text { Floated, } \\
\text { w/o }\end{array}$ & $\begin{array}{c}\text { Cumulative } \\
\text { Amount } \\
\text { Floated, } \\
\text { w/o }\end{array}$ & $\begin{array}{c}\text { Specific Gravity of } \\
\text { Benzene-Bromoform } \\
\text { Solution }\end{array}$ & $\begin{array}{l}\text { Amount } \\
\text { Floated, } \\
\text { w/o }\end{array}$ & $\begin{array}{c}\text { Cumulative } \\
\text { Amount } \\
\text { Floated, } \\
\text { w/o }\end{array}$ & $\begin{array}{c}\text { Specific Gravity of } \\
\text { Benzene-Bromoform } \\
\text { Solution }\end{array}$ & $\begin{array}{l}\text { Amount } \\
\text { Eloated, } \\
\text { w/o }\end{array}$ & $\begin{array}{c}\text { Cumulative } \\
\text { Amount } \\
\text { Floated, } \\
\text { w/o }\end{array}$ \\
\hline 1.857 & 0.04 & 0.04 & 1.867 & 0.59 & 0.59 & 2.000 & 2.54 & 2.54 \\
\hline 1.953 & 0.16 & 0.20 & 1.914 & 0.06 & 0.65 & 2.056 & 0.44 & 2.98 \\
\hline 2.079 & 2.36 & 2.56 & 2.053 & 0.77 & 1.42 & 2. 126 & 5.31 & 8.29 \\
\hline 2.152 & 18.84 & 21.40 & 2.079 & 1.97 & 3.39 & 2.179 & 44.74 & 53.03 \\
\hline 2.195 & 53.19 & 74.59 & 2.118 & 5.99 & 9.38 & 2.216 & 39.40 & 92.43 \\
\hline 2.224 & 22.38 & 96.97 & 2.190 & 45.42 & 54.80 & 2.270 & 7.57 & 100.00 \\
\hline 2.270 & 3.03 & 100.00 & 2.214 & 37.54 & 92.34 & -- & -- & -- \\
\hline-- & -- & -- & 2.278 & 7.66 & 100.00 & -- & -. & -- \\
\hline
\end{tabular}


TABLE A-6. DENSITY DISTRIBUTION OF COMPOSITE SAMPLE OF MINUS 270 PLUS 325-MESH AND MINUS 325-MESH TS-6BF GRAPHITE

\begin{tabular}{|c|c|c|c|c|c|c|c|c|c|c|c|}
\hline \multicolumn{6}{|c|}{$\begin{array}{l}\text { Composite of Minus } 270 \text { Plus } 325-\text { and Minus } 325 \text { Mesh } \\
\text { (From Sample 127-96) }\end{array}$} & \multicolumn{3}{|c|}{$\begin{array}{l}\text { Minus } 270 \text { Plus } 325 \\
\text { (From Sample 127-33) }\end{array}$} & \multicolumn{3}{|c|}{$\begin{array}{c}\text { Minus } 325 \text { Mesh } \\
\text { (From Sample 127-33) }\end{array}$} \\
\hline $\begin{array}{l}\text { Specific } \\
\text { Gravity of } \\
\text { Benzene- } \\
\text { Bromoform } \\
\text { Solution }\end{array}$ & $\begin{array}{l}\text { Amount } \\
\text { Floated, } \\
\text { w/o }\end{array}$ & $\begin{array}{c}\text { Cumulative } \\
\text { Amount } \\
\text { Floated, } \\
\text { w/o }\end{array}$ & $\begin{array}{l}\text { Specific } \\
\text { Gravity of } \\
\text { Benzene- } \\
\text { Bromoform } \\
\text { Solution }\end{array}$ & $\begin{array}{l}\text { Amount } \\
\text { Floated, } \\
\text { w/o }\end{array}$ & $\begin{array}{c}\text { Cumulative } \\
\text { Amount } \\
\text { Floated, } \\
\text { w/o }\end{array}$ & $\begin{array}{l}\text { Specific } \\
\text { Gravity of } \\
\text { Benzene- } \\
\text { Bromoform } \\
\text { Solution }\end{array}$ & $\begin{array}{c}\text { Amount } \\
\text { Floated, } \\
\text { w/o }\end{array}$ & $\begin{array}{c}\text { Cumulative } \\
\text { Amount } \\
\text { Floated, } \\
\text { w/o }\end{array}$ & $\begin{array}{c}\text { Specific } \\
\text { Gravity of } \\
\text { Benzene- } \\
\text { Bromoform } \\
\text { Solution }\end{array}$ & $\begin{array}{l}\text { Amount } \\
\text { Floated, } \\
\text { w/o }\end{array}$ & $\begin{array}{c}\text { Cumulative } \\
\text { Amount } \\
\text { Floated, } \\
\text { w/o }\end{array}$ \\
\hline 1.843 & 0.41 & 0.41 & 2.038 & 2.18 & 2.18 & 1. 643 & 0.32 & 0.32 & 1.877 & 0.31 & 0.31 \\
\hline 1.967 & 0.83 & 1.24 & 2.122 & 2.99 & 5.17 & 1.892 & 0.29 & 0.61 & 1.955 & 0.17 & 0.48 \\
\hline 2.145 & 16.59 & 17.83 & 2.131 & 3.96 & 9.13 & 2.035 & 0.27 & 0.88 & 2.073 & 0.58 & 1.06 \\
\hline 2.205 & 53.74 & 71.57 & 2.151 & 12.13 & 21.26 & 2.100 & 1.22 & 2.10 & 2.126 & 6.61 & 7.67 \\
\hline 2.215 & 9.87 & 81.44 & 2.180. & 25.40 & 46.66 & 2.146 & 6.85 & 8.95 & 2.183 & 24.05 & 31.72 \\
\hline 2.280 & 18.56 & 100.00 & 2.209 & 29.22 & 75.88 & 2.178 & 20.09 & $29: 04$ & 2.232 & 52.90 & 84.62 \\
\hline-- & -- & -- & 2.239 & 23.66 & 99.54 & 2.244 & 67.01 & 96.05 & 2.280 & 15.38 & 100.00 \\
\hline-- & -- & - & 2.281 & 0.46 & 100.00 & 2.278 & 3.95 & 100.00 & -. & -. & - \\
\hline
\end{tabular}




\section{A -8}

During this month, work was begun on revising the existing digital program so that it could be applied to the PRTR. In conjunction with this revision, the various physical constants needed for the program are being converted to a suitable form.

During the next month, it is expected that the revision of the program will be completed, and all the constants and other inputs will be available. The program will then be checked in operation prior to beginning the actual computation of incidents. 
$\mathrm{B}-1$ and $\mathrm{B}-2$

\title{
B. DEVELOPMENTS FOR ALUMINUM-CLAD FUEL ELEMENTS
}

\author{
Preparation of Aluminum-Uranium Alloys
}

N. E. Daniel, E. L. Foster, and R. F. Dickerson

One method of increasing a reactor's fuel loading is to increase the uranium content of its fuel. This approach is contemplated in certain reactors using aluminumurarium-alloy fuels. One reactor concept would utilize these fuels in the form of hollow cylindrical tubes clad inside and out with aluminum. The proposed fabrication techniques require a hollow cylindrical alloy billet suitable for coextrusion with the aluminum cladding. A program of research concerned with the development of casting techniques for the production of such billets containing high concentrations of uranium and with improving the fabrication characteristics of these alloys is in progress.

Research on the casting of hollow aluminum- $35 \mathrm{w} / \mathrm{o}$ uranium extrusion billets has been concerned with the utilization of bottom-pouring techniques in conjunction with a movable pouring spout feeding into a horizontal centrifugal mold. The results of tests with this centrifugal casting apparatus have been inconclusive. Tests now in progress shovld demonstrate the feasibility of the techniques employed.

$\mathrm{X}$-ray diffraction studies and metallographic examination of alloys containing terniry additions have been completed. The effects of $3 \mathrm{w} / \mathrm{o}$ additions of germanium, lead, niobium, palladium, silicon, tin, and zirconium on the lattice constants of the UAl have been studied. It was found that germanium had little or no effect on lattice constants, but no $\mathrm{UAl}_{4}$ was found in the specimens. Lead, niobium, and palladium reduce the $\mathrm{UAl}_{3}$ lattice constants and the specimens contain some $\mathrm{UAl}_{4}$. Silicon, which also reduces the $\mathrm{UAl}_{3}$ lattice constants, completely inhibits the formation of $\mathrm{UAl}_{4}$, as does zirconium. Tin, which increases the lattice constant of the $\mathrm{UAl}_{3}$, also completely inhikits the formation of $\mathrm{UAl}_{4}$.

Since these alloy additions inhibit the formation of $\mathrm{UAl}_{4}$ in favor of $\mathrm{UAl}_{3}$ and in som? cases refine the primary particle size, a series of 3-in.-diameter castings 12 in. long is being made. These ingots will be examined by radiographic techniques and a part of each casting will be extruded utilizing reduction's up to 16:1. Metallographic exancination will be made on specimens from the as-cast ingot and from extruded rod.

Further casting studies will be concerned with perfecting the bottom-pouring techniqu's now being developed and with the production of extrusion billets containing ternary addiiions. The evaluation of the alloys containing ternary additions will include radiographic examinations of homogeneity, fabricability studies by extrusion, and tensile test: to determine if the material is strain-rate sensitive. 
0

$\bullet$ 


\author{
C- 1 \\ C. RADIOISOTOPE AND RA.DIATION APPLICATIONS \\ P. Schall
}

Studies on radiometric titrations and ion-exchange separation of magnesium in cement continue to yield promising results. Some additional research is planned on pos:ible interference of other constituents ir cement. Further studies on radiometric and activation analysis of other cement constituents are also in progress.

The program on survey and selection of suitable processes for application of intrinsic radioactive tracers was continued.

The analysis of urea-hydrocarbon inclusion compounds is continuing. Amide forruation has been verified in dodecane, decane, cetane, and octane complexes. The forration of amides is characterized by low G-values. A typical complex, ureadodecane, has been analyzed in sufficient detail to show that the nature and yield of hydr:ocarbon degradation products is similar to that found in uncomplexed dodecane. A more detailed study of urea complexes of octane and dodecane and a new study of a nickel cyanide-benzene complex are in progress.

\title{
Development of Raclioactive-Tracer Quality-Control Systems
}

J. E. Howes, T. S. Elleman, C. T. Brown, D. N. Sunderman, and M. Pobereskin

Further refinement of the method developed for the analysis of magnesium in cement is in progress. A detailed study is being made of the precision of the method over a wide range of magnesium concentration. The effect of the interfering elements, calcium and iron, will be investigated. The effect of aluminum, ammonia, arsenic, nitrate, potassium, silicate, sodium, and sulfate which may not interfere, but are presient in cement, will also be studied.

Exploratory work is being done on radiometric methods for the determination of alurainum, calcium, and iron. Each of these may be determined by titration with ethylene diamine-tetracetic acid (EDTA). A possible end-point indicator is water-insoluble silver-110 iodate. The silver-EDTA complex is much less stable than those of aluminum, calcium, and iron. The silver will not: complex and go into solution until all the alurinum, calcium, or iron is complexed. A rapid rise of activity in the solution indicates the end point of the titration.

Further work on the activation analysis of cement has confirmed previous results. Marganese and sodium give satisfactory analyses, but the calcium and aluminum results are consistently low. An evaluation of the $(r, p)$ reaction on magnesium and the $(n, \alpha)$ reaction on aluminum has shown that 50 per cent of the sodium-24 activity may be attributed to these nuclear reactions. 
Future work will consist of a comparison of various irradiated standards in order to evaluate any intrinsic error in the activation-analysis technique. Irradiations will be performed in a region of low fast flux to minimize $(n, \alpha)$ and $(n, p)$ reactions. Raw materials us ed in the manufacture of cement will be obtained and the activation-analysis technique evaluated with these less complex mixtures.

\section{Use of Intrinsic Radioactive Tracers for Process Control}

D. N. Sunderman, T. S. Elleman, R. H. Barnes, J. L. McFarling, and M. Pobereskin

The research program to investigate and develop methods to use intrinsic radioactive tracers in process control is continuing. Current emphasis in this program is concentrated along two lines of endeavor. First, a detailed study of the unit operations and unit processes in chemical engineering is under way to determine those processes most suitable for radioactive tracer control. Second, an evaluation of the processes used in ten high-volume industries to determine process-control requirements and possibilities for radiotracer control is being continued.

Completion of both of the phases mentioned is expected during the next month. It is expected that a tentative choice of the process for intensive study will also be carried out by the end of the next report period.

\section{$\underline{\text { Radiation Chemistry of Inclusion Compounds }}$}

M. J. Oestmann, R. J. Jakobsen, E. J. Kahler, and W. S. Diethorn

During January infrared and gas-chromatography analyses of irradiated dodecane, decane, cetane, and octane, and their urea complexes, were continued. The spectrum of radiolysis products in each system has not been mapped out in detail, but sufficient information is now available to define the major products and their yields. This information provides a basis for a comparison of the radiation chemistry of the complexed and uncomplexed hydrocarbons.

\section{Summary of Current Work}

A satisfactory scheme of separating and analyzing the entire spectrum of radiolysis products in each irradiated sample has not been developed. Only relatively small samples of the irradiated materials have been available, and this has hampered both the search for a good separation and analytical scheme, and the quantitative recovery of radiolysis products. In the current program no attempt has been made to identify and measure gaseous radiolysis products. The nature of gaseous products can be predicted and, in this stage of the program, gas yields are of little value in the interpretation of the irradiation results. 


\section{$\mathrm{C}-3$}

The hydrocarbon phase is separated from an irradiated urea complex by dissolving the complex in water and extracting with pentane. The pentane extract contains the parent hydrocarbon and the radiolysis products. Infrared and gas-chromatography analyses are performed on the pentane extract without further separation. The yield of amide is determined by infrared techniques. This radiolysis product masks unsaturation so the amount of unsaturated hydrocarbon cannot be determined by this method. Gas chromatography does not resolve saturated and unsaturated species having the same nurber of carbon atoms. Accordingly, only the total amount of a hydrocarbon product of given chain length (saturated plus unsaturated) is reported.

The amounts of amide produced in four urea complexes, irradiated to $2 \times 10^{8}$ rads, are reported in Table C-1. In the G-value calculations the amide is assumed to be entirely the amide of the parent hydrocarbon. If lower-molecular-weight amides are pre:s ent, these G-values are too small. However, large upward revisions in the Gvalues would only be necessary if the amide consisted of chiefly very low-molecularweight species. This latter molecular-weiglat distribution is considered unlikely.

TABLE C-1. AMIDE FORMATION IN IRRADIA TED UREA COMPLEXES

\begin{tabular}{|c|c|c|c|c|c|}
\hline \multirow[b]{2}{*}{ Hydrocarbon } & \multirow[b]{2}{*}{ Formula } & \multicolumn{2}{|c|}{$\begin{array}{l}\text { Weight Ratis of Urea to } \\
\text { Hydrocarbon in Complex }\end{array}$} & \multirow{2}{*}{$\begin{array}{c}\operatorname{Amide}_{\mathrm{w} / \mathrm{O}}^{(\mathrm{a})} \\
\end{array}$} & \multirow[b]{2}{*}{$G$-Value $(b)$} \\
\hline & & Literature & Experimental & & \\
\hline Dodecane & $\mathrm{C}_{12} \mathrm{H}_{26}$ & 3.3 & 2.6 & $5-10$ & $1.4-2.8$ \\
\hline Decane & $\mathrm{C}_{10} \mathrm{H}_{22}$ & 3.4 & 3.4 & $5-10$ & $1.7-3.4$ \\
\hline Octane & $\mathrm{C}_{8} \mathrm{H}_{18}$ & 3.5 & 3.3 & $5-10$ & $2.0-4.0$ \\
\hline Cetane & $\mathrm{C}_{16} \mathrm{H}_{34}$ & 3.2 & 3.3 & $5-10$ & 1. $1-2.2$ \\
\hline
\end{tabular}

(a) Weight per cent of amide in extracted hydrocarbon phase.

(b) Molecules of amide per $100 \mathrm{ev}$ absorbed in hydrocarbon component of urea complex.

The distribution and yield of hydrocarbon products in the irradiated complexes is best described in terms of the gas-chromatography results on irradiated samples of complexed and uncomplexed dodecane. Irradiation results for uncomplexed octane, decane, and cetane are available but the results for the complexed hydrocarbons are not, so these three hydrocarbons are not reported. Results for uncomplexed dodecane, irradiated to $2 \times 10^{8} \mathrm{rads}$, are summarized :in Table $\mathrm{C}-2$.

The carbon-skeleton designation for each component in Table C-2 groups saturated and unsaturated species together because, as discussed above, gas chromatography does not :esolve saturation and unsaturation. Chromatograms of the hydrocarbon phase separated from complexed dodecane, irradiated to the same dose, exhibit the same spectrum of products reported for uncomplexed dodecane in Table C-2. The yields and the $(\xi$-values are smaller, however. 


$$
\mathrm{C}-4
$$

TABLE C-2. YIELD OF HYDROCARBONS IN IRRADIATED DODECANE

\begin{tabular}{ccc}
\hline Component & Amount, w/o & G-Value (a) \\
\hline$C_{12}$ & 98.7 & - \\
$C_{11}$ & -- & - \\
$C_{10}$ & 0.2 & 0.08 \\
$C_{9}$ & 0.2 & 0.09 \\
$C_{8}$ & 0.2 & 0.10 \\
$C_{7}$ & 0.2 & 0.11 \\
$C_{6}$ & 0.2 & 0.13 \\
$C_{5}$ & 0.2 & 0.16 \\
$C_{4}$ & 0.1 & 0.10 \\
\hline \hline
\end{tabular}

(a) Molecules of component produced per $100 \mathrm{ev}$ absorbed in parent hydrocarbon in the complex.

The current work shows that amide formation is a typical radiation-induced reaction in urea-hydrocarbon complexes. G-values are low. On the basis of results with a typical urea complex, urea-dodecane, the formation and yield of hydrocarbon degradation products appear to be very similar to those found in irradiated, uncomplexed hydrocarbons.

\section{Future Work}

Larger batches of urea complexes of dodecane and octane are being prepared for irradiation in order to make a more quantitative study of the nature and yield of radiolysis products. This latter study will complete the program on urea complexes. A different type of inclusion compound has been selected for study also. An inclusion compound of nickel cyanide and benzene, $\mathrm{Ni}\left(\mathrm{NH}_{3}\right)(\mathrm{CN})_{2} \cdot \mathrm{C}_{6} \mathrm{H}_{6}$, will be investigated. In this complex the guest material is aromatic and it is hoped that radiation will promote the addition of a $\mathrm{NH}_{2}$ or $\mathrm{CN}$ group to the benzene ring. 


\section{$\mathrm{D}-1$ \\ D. PROCESSING OF FEED MATERIALS}

E. L. Foster

National Lead Company of Ohio produces uranium ingots that ultimately are fabriciated to fuel slugs. The qualities of the finished slug are dependent, to some extent, upon the qualities of the ingot. A program presently in progress is concerned with the faciors that affect the solidification of large castings. A convenient method of evaluatir.g factors present in the casting procedure used at this time, as well as in future casting procedures, is desired.

\section{Solidification of Uranium}

E. L. Foster, C. K. Franklin, B. L. Fletcher, A. B. Pritsker, and R. F. Dickerson

The manner in which uranium metal solidifies in cylindrical graphite molds is under study. Since the contained heat of the materials involved controls solidification, a mathematical model has been developed which predicts the transfer of heat in the mold and ingot during the freezing period. One-hundred-pound melts of uranium are being cast to measure the temperature of the ingot, mold, and furnace from pour. The the: mal data, so obtained, will be used to refine and check the computed data from the mathematical model. One-hundred-pound heats are also being poured to study the events occurring at the interface of the mold and ingot.

The metal is melted and cast in graphite coated with $\mathrm{MgO}$ wash. A pouring temperature of $2550 \mathrm{~F}$ is used, with the liquid held at temperature for 5 min before pour. For the study of the phenomena that occur at the mold-metal interface, a network of elestrical probes is arranged along the length of the mold flush with the inner surface. These probes, operating at $8 \mathrm{v}$, register the time that the liquid or solid is in electrical contact with the mold wall. Four castings have been poured with ten probes situated in the mold wall and spaced 2 in. apart. The probe connections are brought out to an event-type recorder which records simultaneously the happenings at each contact poirt.

In investigating the formation of a mold-metal gap the recorder was adapted so that it registered events that occurred during a 5-min period immediately after pouring. The recorder indicated that

(1) The probes stationed at 2 and 4 in. above the bottom of the ingot registered contact during the entire test period; therefore, in this area, the ingot is in contact with the mold wall.

(2) Along the central length of the ingot a separation of the mold and ingot occurred 30 to $60 \mathrm{sec}$ after pouring.

(3) The top portion of the mold wall separated 5 to 30 sec after pouring. 
$\mathrm{D}-2$

The probes located along the central length of the mold showed short cyclical periods of contact and subsequent breaks in contact. During these periods, lasting from 3 to $10 \mathrm{sec}$, the metal touched the probes and then shrank away. Because of this observation, further investigation will be made to more thoroughly define the sequence of these events. The placement of two or more probes on one horizontal plane around the mold may more clearly establish what is occurring as the metal freezes.

The results from the original time-temperature casting studies have been partially evaluated and indicate that a considerable temperature lag was caused by the physical make-up of some of the thermocouple probes. These probes have been redesigned and a new series of experiments has been started to measure the temperature in the ingot, mold, and furnace as the liquid cools. New temperature-decay curves of the ingot will be developed from these experiments. The melts are cast under the same procedures as those used in the mold-ingot-gap experiments. One ing has been cast.

The mathematical model has been rescaled to the size of the experimental castings, and a preliminary run on the computer has been completed. This computer run was made to check the operation of the program and to study the convergence and stability of the solution for various time intervals. It was found that during the pouring of the casting use of a time interval of $1 \mathrm{sec}$ caused unrealistic temperature oscillations. The calculation was then repeated with a starting time interval $(\Delta \theta)$ of $0.5 \mathrm{sec}$, and the temperature values in the mold and casting during the pour were found to vary in a more realistic manner. After completion of pouring, the time interval was increased to $1 \mathrm{sec}$ since the interface temperatures (mold and casting) were not varying so rapidly. This interval was found to be satisfactory, and after $15 \mathrm{sec}$ of elapsed time the time increment was again increased to $2 \mathrm{sec}$. Here again it was found that temperature oscillations were produced, and the interval was reduced to $1 \mathrm{sec}$. After $100 \mathrm{sec}$ had elapsed, all temperatures were found to be varying smoothly, and a 5-sec increment was tried; this halted the computation because the oscillations produced negative temperature values.

This first analysis with the mathematical model scaled down to the 100-1b casting size was made primarily to check the behavior of the numerical analysis for various time intervals. This is of importance in that knowledge of the correct time interval to use affects the efficiency of the calculation; e.g., if l-sec intervals (in place of $0.5 \mathrm{sec}$ ) can be used after the pouring is completed, the solution proceeds twice as fast. 


\section{E-1 and E-2 \\ E. SPRAY DEPOSITION OF CALCIUM METAL ON NICKEL OR INCONEL}

R. M. Evans and R. E. Monroe

Calcium metal coatings on nickel and nickel alloys in their present state of development do not perform consistently. It is the objective of this investigation for the Sandia Corporation to evaluate arc spraying of calcium as a means for producing better coatings. The arc-spraying method to be used is essentially that developed at Bat:elle several years ago. An electric arc is used to melt calcium metal in an inertgas atmosphere and the same gas is used to atomize and propel the molten metal.

Initial effort has been directed toward redesigning and rebuilding existing equipmert. This alteration program was necessary to make the equipment suitable for spraying calcium. Construction after redesign has now begun. Sources for calcium metal wire, thin nickel, and Inconel strip have been found and the materials for the expırimental program were ordered. 
0

$\theta$ 
F-1

\section{F. RESEARCH FOR AEC REACTOR DEVELOPMENT DIVISION PHOGRAM}

S. J. Paprocki and R. F. Dickerson

REACTOR MATERIALS AND COMPONENTS

R. F. Dickerson

In an attempt to reduce the amount of trivalent $\mathrm{La}_{2} \mathrm{O}_{3}$ or $\mathrm{Y}_{2} \mathrm{O}_{3}$ needed to stabilize $\mathrm{UO}_{2}$, divalent $\mathrm{CaO}$ is being added. A number of mixtures have been fabricated and analyzed by $\mathrm{X}$-ray diffraction. Initial resultis on the $\mathrm{La}_{2} \mathrm{O}_{3}-\mathrm{CaO}$ additives are promising, while those obtained from oxidation tests on $\mathrm{Y}_{2} \mathrm{O}_{3}-\mathrm{CaO}$ mixtures show that bodies are reduced to powder in less than $1 \mathrm{hr}$ at $1650 \mathrm{C}$ in air. During the course of the high-pressure high-temperature solid-state study, $\mathrm{U}_{3} \mathrm{O}_{8}$ has been utilized to study reactions with other oxides; however, under conditions of high temperature and pressure a new phase was formed. This phase exists at over 16,000 atm above $400 \mathrm{C}$ in a well-crystallized form. Tests indicate that an elevated temperature, as well as pressur $\epsilon$, is needed to effect the transformation to the phase. Thermal gravimetric analysis is hows the composition of the new phase to be $\mathrm{UO}_{2.65}$.

Completion of the $570 \mathrm{C}$ is otherm for the zirconium-25 w/o uranium alloy will complete this phase of the fueled zirconium hydride moderator program. The capsules containing the zirconium- $2 \mathrm{w} / \mathrm{o}$ uranium alloy hydride are in their sixth cycle in the MTR. The temperature readings of one of the capsules have declined and this capsule will be relocated to bring about increased ternperatures.

Eight capsules containing Type 347 stainless steel have been removed from the F-10 position in the ETR so that the KAPL-33 loop can be installed. They will be relocated in the K-7 position. Five dosimeter assemblies were exposed in the F-10 position and are being returned for evaluation. A nonlead capsule designed to gamma heat to $600 \mathrm{~F}$ has been exposed for 1 cycle. Examination of the capsules shows the lead temperature monitors were melted, indicating temperatures above $635 \mathrm{~F}$; howevej, temperatures did not approach the melting point of aluminum.

The consumable-electrode arc melting of niobium-base alloys to be investigated as possible claddings for EBR advanced fuel elements is progressing. The preparation of the necessary electrodes is particular:ly difficult for the titanium-niobium alloys. It is planned to break down the initial cast structure by upset forging of the ingcts. These materials will be protected from oxidation by molybdenum capsules. 


\author{
$\mathrm{F}-2$ \\ Valence Effects of Oxide Additions to Uranium Dioxide
}

W. B. Wilson, A. Gerds, and C. M. Schwartz

Work has continued on development of a stabilized high-temperature nuclear fuel capable of operation in either oxidizing or reducing atmospheres. Previous work has shown that when $\mathrm{UO}_{2}$ is heated in air at temperatures of the order of $1200 \mathrm{C}$ and above transformation to $\mathrm{U}_{3} \mathrm{O}_{8}$ occurs. $\mathrm{U}_{3} \mathrm{O}_{8}$ has a higher vapor pressure, and volatilization of the oxide results. The experimental approach utilized to overcome this difficulty has been to react $\mathrm{UO}_{2}$ with various oxide additives. It was found that definite benefit is obtained when $\mathrm{UO}_{2}$ is reacted with trivalent oxide additions of specific composition. $\mathrm{UO}_{2}$ plus 58 mole per cent of $\mathrm{La}_{2} \mathrm{O}_{3}$ or $\mathrm{Y}_{2} \mathrm{O}_{3}$ exhibits low volatility and no gros s change in crystal structure upon oxidation for $20 \mathrm{hr}$ at $1650 \mathrm{C}$. However, these materials are oxidized, resulting in a change in lattice parameter. The first phase of this investigation has been directed toward obtaining more fundamental knowledge of the part that the additive oxide plays in achieving stabilization.

The current phase of this investigation has as its objective the reduction of the large amount of additive required to achieve stabilization. A working hypothesis had been formulated on the binary systems that the additive can compensate for the valence change in the uranium that occurs upon oxidation. Using this hypothesis, attempts will be made to substitute, in part, divalent material such as $\mathrm{CaO}$ for trivalent oxides such as $\mathrm{La}_{2} \mathrm{O}_{3}$ or $\mathrm{Y}_{2} \mathrm{O}_{3}$. If solid solutions can be maintained, the same relative amount of $\mathrm{CaO}$ should be more effective than the $\mathrm{La}_{2} \mathrm{O}_{3}$ and will possibly permit reduction of the over-all amount of additive required for stabilization.

Specific $\mathrm{UO}_{2}-\mathrm{La}_{2} \mathrm{O}_{3}-\mathrm{CaO}$ and $\mathrm{UO}_{2}-\mathrm{Y}_{2} \mathrm{O}_{3}-\mathrm{CaO}$ compositions have been prepared. These are, as mixed, in mole per cent:

$$
\begin{aligned}
& \mathrm{UO}_{2}-30 \mathrm{La}_{2} \mathrm{O}_{3}-5 \mathrm{CaO} \\
& \mathrm{UO}_{2}-30 \mathrm{La}_{2} \mathrm{O}_{3}-10 \mathrm{CaO} \\
& \mathrm{UO}_{2}-40 \mathrm{La}_{2} \mathrm{O}_{3}-5 \mathrm{CaO} \\
& \mathrm{UO}_{2}-25 \mathrm{Y}_{2} \mathrm{O}_{3}-15 \mathrm{CaO} \\
& \mathrm{UO}_{2}-20 \mathrm{Y}_{2} \mathrm{O}_{3}-20 \mathrm{CaO} \\
& \mathrm{UO}_{2}-30 \mathrm{Y}_{2} \mathrm{O}_{3}-10 \mathrm{CaO} \\
& \mathrm{UO}_{2}-30 \mathrm{La}_{2} \mathrm{O}_{3}-50 \mathrm{ThO}_{2}
\end{aligned}
$$

The last composition does not fit the series, but is of interest as a possible improved breeder fuel.

The above materials have been prepared and analyzed by X-ray diffraction, but only preliminary work has been carried out on evaluation under oxidizing conditions.

Previous results have been reported on $\mathrm{UO}_{2}-30 \mathrm{La}_{2} \mathrm{O}_{3}-5 \mathrm{CaO}$, which has indicated promise. The preliminary results on the $\mathrm{UO}_{2}-\mathrm{Y}_{2} \mathrm{O}_{3}-\mathrm{CaO}$ system have shown that 
F-3

bodies of these materials are reduced to powder in less than $\mathrm{l} \mathrm{hr}$ at $1650 \mathrm{C}$ in air. The reasons for this must await analysis, but it appears possible that the CaO comes out of solid solution upon oxidation and the remaining material is insufficiently stabilized.

In previous work it had been shown that the fluorite structure can be retained in both oxidized and reduced solid solutions. The quaternary materials, however, in the reduced state have the body-centered-cubic rare-earch "C" structure which requires a doubled cell size with respect to that of the fluorite structure. It may be viewed as a defect fluorite structure with an ordering of the vacancies. In the quaternary solid solutions, ordering of both vacancies and cations may occur, requiring the doubled cell size. The effect of this structúre on stabilization is unknown. Work will continue to determine the reactions that occur in these materials upon oxidation.

\section{High-Pressure High-Temperature Solid-State Studies}

\section{W. B. Wilson and C. M. Schwartz}

The present program was initiated to assess the potential capabilities of produciag super refractory materials for reactor components through the simultaneous application of ultrahigh pressure and temperature. A systematic investigation of the reaction of uranium oxide with other oxide systems while under pressure was inaugurated to obtain a more fundamental insight of the general effects of ultrahigh pressure.

During the course of the research, it appeared desirable to utilize $\mathrm{U}_{3} \mathrm{O}_{8}$ in preference to $\mathrm{UO}_{2}$ for reactions because of ion-size-factor consideration. A new phase was repeatedly produced when $\mathrm{U}_{3} \mathrm{O}_{8}$ was subjected to high pressures and temperatures. Thu:;, under conditions of high pressures and high temperatures, the new phase exists duriag attempts to perform reactions. Because of the importance of this phase to the desired reactions, a study of the pressure-temperature phase diagram for $\mathrm{U}_{3} \mathrm{O}_{8}$ was initiated.

Previous research using single crystals grown from the vapor had indicated that $\mathrm{U}_{3} \mathrm{O}_{3}$ can exist in at least two allotropic modifications, subject to formative conditions.

The existence region of the third high-pressure modification of $\mathrm{U}_{3} \mathrm{O}_{8}$ has been defined at the lower limit of pressure and ternperature, using X-ray diffraction postexaraination at ambient pressure and temperature. At 10,000 atm and temperatures to 51)0 C, only the alpha modification of $\mathrm{U}_{3} \mathrm{O}_{\varepsilon}$ was detected. At 16,000 atm at ambient temjerature the first appearance of a transition structure leading to the new phase of $\mathrm{U}_{3} \mathrm{O}_{8}$ was detected. At $400 \mathrm{C}$ the new phase was sharply defined. At pressures greater than 16,000 atm the new phase existed above $400 \mathrm{C}$ in well-crystallized form. At inte::mediate temperatures at both 16,000 and 25,000 atm the crystal structure assumed near ly amorphous characteristics, indicating, that transformation from alpha to the new high-pressure modification was occurring. To determine if the new phase is sluggish in transformation due to pressure, in the $\mathrm{Br}$ idgman sense, $\mathrm{U}_{3} \mathrm{O}_{8}$ was subjected to $100,000 \mathrm{~atm}$ at room temperature for over $17 \mathrm{hr}$. The results clearly indicate that this is nist the case and that an elevated temperatıre is required to effect the transformation. 


$$
\mathrm{F}-4
$$

It was previously thought that the new phase was intermediate between $\mathrm{UO}_{2}$ and $\mathrm{U}_{3} \mathrm{O}_{8}$ and that $\mathrm{U}_{3} \mathrm{O}_{8}$ possibly decomposed to $\mathrm{UO}_{2}$ under pressure in accord with the Clapeyron relation. Thermal gravimetric analysis of the new phase, however, shows that its composition is $\mathrm{UO}_{2} .65$ and that the decomposition does not, in fact, occur. Examination of the specimen from which decomposition of the $\mathrm{U}_{3} \mathrm{O}_{8}$ to $\mathrm{UO}_{2}$ was observed earlier indicated that the $\mathrm{BeO}$ sleeve liner may have ruptured and allowed reduction by the heater material.

The $\mathrm{U}_{3} \mathrm{O}_{8}$ pressure-temperature phase diagram will be extended to higher pressures and temperatures. Studies on high-pressure reactions are being continued. Modifications are nearly completed to permit the advanced die to be used in a 750-ton press to determine its ultimate pressure capabilities.

Fueled Zirconium Hydride Moderator

H. E. Bigony, A. K. Hopkins, and H. H. Krause

Progress in the study of potential fueled moderators has continued with the determination of hydrogen-absorption isotherms for the zirconium- $25 \mathrm{w} / \mathrm{o}$ uranium alloy, and high-temperature X-ray diffraction patterns of hydrides of that alloy. The capsules containing specimens of the $2 \mathrm{w} / 0$ uranium alloy for radiation-damage studies are now in their sixth cycle in the MTR.

Structure and Pressure-CompositionTemperature Studies

The hydrogen-absorption isotherm at $835 \mathrm{C}$ for the zirconium-25 w/o uranium alloy was determined, and the phase boundary limits were obtained from Sieverts plots. Data indicating the phase boundaries are given in Table F-l. The determination of the $570 \mathrm{C}$ isotherm, which is in progress, will complete this phase of the program.

TABLE F-1. PHASE BOUNDARIES IN THE ZIRCONIUM-25 w/o URANIUM ALLOY HYDRIDE SYSTEM AT $835 \mathrm{C}$

\begin{tabular}{ccc}
\hline Phase Boundary & $\begin{array}{c}\text { Hydrogen Absorption, } \\
\mathrm{cm}^{3} \text { per g }\end{array}$ & $\begin{array}{c}\text { Pressure, } \\
\text { cm of mercury }\end{array}$ \\
\hline 1 & 40.6 & 5.0 \\
2 & 48.8 & 5.0 \\
3 & 93.8 & 26.8 \\
4 & 136.0 & 28.3 \\
\hline
\end{tabular}

$X$-ray diffraction patterns of the hydrided zirconium-25 w/o uranium alloy were taken in the 400 to $800 \mathrm{C}$ temperature range. Analysis of similar data previously obtained for the $\mathrm{I}$ and $50 \mathrm{w} / 0$ alloys is nearing completion. 
$\mathrm{F}-5$

Radiation-Dama'ge Studies

Capsules BMI-20-1 and BMI-20-2, both of which contain zirconium hydride and fueled specimens of zirconium-2 w/o uranium alloy hydride, are now in their sixth cycie in the MTR. Temperature ranges recorded during January were as follows:

\begin{tabular}{|c|c|c|}
\hline Capsule & Thermocouple 1 & Thermocouple 5 \\
\hline BMI-20-1 & $1210-1260 \mid$ & $1120-1175 \mathrm{~F}$ \\
\hline BMI-20-2 & $950-1060 \mathrm{~F}$ & $1150-1195 \mathrm{~F}$ \\
\hline
\end{tabular}

Inasmuch as there has been a decline in temperature for Capsule BMI-20-1 during the month, appropriate relocation measures are being taken to bring about a return to higher levels.

Irradiation Surveillance Program on Type 347 Stainless Steel

F. R. Shober, F. A. Rough, and R. F. Dickerson

The effect of fast-neutron flux on the mechanical properties of AISI Type 347 stainless are being determined and evaluated. The tensile, cyclic-strain fatigue, and impizt properties are to be determined after exposures to a neutron flux at 120 and $600 \mathrm{~F}$. These data should give a measure of irradiation damage to be expected in the KAF'L-33 loop to be inserted in the F-10 position of the ETR. It is planned to determin's these properties after a period of exposure representing 6 months of service in the E-10 position and after successive 6-month intervals for times up to 3 years of totai. exposure.

The eight capsules being irradiated at process water temperature, approximately $120 \mathrm{~F}$, have been moved from the F-10 position to the K-7 position. The F-10 position was vacated in order that the in-pile portion of the KAPL-33 loop could be installed. The relative position of the capsules with respect to top and bottom of the test hole are the isame. It is expected that one capsule containing tensile and cyclic-strain fatigue specimens and one containing impact specimens will be discharged in June, 1959. The totaj exposure of these eight capsules will be calculated on the basis of ETR flux data obtained during Cycle 4, evaluation of dosimeters exposed during Cycles 10 and 11 , and subsequent evaluation of dosimeters in the $\mathrm{K}-7$ position.

The five dosimeter as semblies were exposed in F-10 position before the capsules wera moved to the $\mathrm{K}-7$ position. The assemblies consisted of thin-walled aluminum tubiug into which had been placed short nickel wires and crystals of ammonium sulfate in irdividual quartz vials. The exposed dosimeters are being returned to Battelle for evaluation. Five additional dosimeter as semblies have been prepared and shipped to the ITR to be inserted in the core-filler piece to monitor and map the fast flux of the $\mathrm{K}-7$ position. A new lifting pin in the core-filler piece should now permit loading of a dosimeter assembly into the center hole. Upon completion of mapping the fast flux (>l unev) of the K-7 position, dosimeters will be used in the center hole only to determine: the flux from cycle to cycle. 
F-6

Calculations based on the total-exposure data of the cold capsules indicate that in order to accumulate irradiation damage and to determine its effects at a rate which will provide irradiation-damage data to insure safe operation of the KAPL-33 in-pile tube, a fast flux of $4 \times 10^{14} \mathrm{n} /\left(\mathrm{cm}^{2}\right)(\mathrm{sec})$ (neutrons having energies greater than $1 \mathrm{Mev}$ ) is necessary. The capsules at the top and bottom of the test position do not receive peak flux and hence their cumulative dosages will not maintain the 6-month lead time over the in-pile tube necessary to insure safe operation of the tube. Efforts will be made to insert all eight capsules in a position of peak flux in the K-7 position to take advantage of as high a fast flux as is available at this position.

A nonlead capsule, BMI-24-1, designed to operate at $600 \pm 100 \mathrm{~F}$ was exposed for one cycle in the F-10-NW position. The loading and irradiation of this nonlead capsule was made in an effort to determine whether conditions that caused the excessive temperatures in Capsule BMI-24-17 continue to exist in the F-10 position. It has been returned to the Battelle Hot Cell, opened, and examined. The temperature monitor containing the lead powder was opened and found to have melted. The lead particles had agglomerated, indicating the temperature had been in excess of $635 \mathrm{~F}$. The other temperature monitors containing lower melting alloys and materials were not examined. The surfaces of the aluminum inserts in contact with the stainless steel specimens were examined carefully for evidence of melting. There were no melted areas evident. Apparently, the condition that produced melting in Capsule BMI-24-17 does not exist continually in the F-10 position. The duplicate of Lead Capsule BMI-24-17 is being made and will be shipped to the ETR.

\section{STUDIES OF ALLOY FUELS}

R. F. Dickerson

The melting and casting of all required niobium-uranium alloys has been completed. Eighteen 2-in. -diameter right-cylinder ingots have been prepared by double consumable-electrode arc melting. Alloys containing $30 \mathrm{w} / 0$ uranium have been hot worked by hammer forging at $2550 \mathrm{~F}$; however, this is a marginal fabrication temperature and better results could be obtained at higher temperatures. Attempts were made to hot work alloys containing 40,50,60, and 70 w/o niobium by press forging at $2400 \mathrm{~F}$. This temperature is not suitable for fabricating these alloys. No evidence to support the existence of a ductile-brittle transition has been found as yet.

In the study of thorium-uranium alloys, improvement in the corrosion resistance of thorium has been achieved by alloying. A furnace-cooled thorium-25 w/o uranium$25 \mathrm{w} / 0$ zirconium alloy is believed to have performed well because of a partial network of zirconium-uranium in the structure which acts as a barrier to corrosion. 
F-7

Development of Niobium-Base Alloys

E. J. Jablonowski, F. R. Shober, and R. F. Dickerson

Niobium and niobium-base alloys are potentially suitable materials for cladding purposes in reactors operating at elevated temperatures. Several niobium-base alloy systems are being considered for physical- and mechanical-property evaluation with respect to cladding applications in fast reactors. In addition to niobium and a comparison alloy of vanadium-10 w/o titanium-l. w/o niobium, the following alloys have been selected for study: niobium-4.5 w/o zirconium, niobium-1 w/o and niobium-2 $\mathrm{w} / \mathrm{c}$ chromium, niobium $-40 \mathrm{w} / 0$ titanium- $10 \mathrm{w} / 0$ aluminum, niobium-20 w/o titanium$1.5 \mathrm{w} / 0 \mathrm{chromium}$, and niobium $-10 \mathrm{w} / 0$ tantalum-2 w/o chromium. The fabricability, weldability, thermal conductivity, and mechanical strength of the alloys will be examined.

The alloys will be prepared as 1 to $2-\mathrm{kg}$ heats by consumable-electrode arcmelting techniques. Each alloy will be melted twice to insure homogeneity. Electrodes are being prepared from sintered niobium bars, sheet aluminum, tantalum, and zirconium, iodide chromium, and titanium and vanadium chips. Nominal metal and gaseous impurity levels of niobium and the alloying elements are less than $0.2 \mathrm{w} / 0$. Electrodes of niobium-4.5 w/o zirconium, niobium- $1 \mathrm{w} / 0$ and niobium-2 w/o chromium, and niobium $-10 \mathrm{w} / 0$ tantalum $-2 \mathrm{w} / 0$ chromium have been prepared by fusing the sheet or crystal alloying additions to the niobium bars. Since chromium losses by volatilizatior: during melting are expected, chromium was overcharged up to 100 per cent of the required alloy additions. Attempts will be made to prepare the remaining niobiumbase alloys by cold die pressing the alloying addition around the sintered niobium bar. If pressing fails to produce a dense electrode, the alloys will be arc-melted into $150-\mathrm{g}$ finger bars which will be fused end-to-end to form an electrode. No difficulty is expected in preparing the vanadium-base alloy electrode by cold die pressing.

The cast structure of the arc-melted alloys will be broken up by upset hammer forging at 1000 to $1400 \mathrm{C}$. Molybdenum capsules will be used to protect and laterally restrain the cast alloys during hot fabrication. Eight molybdenum capsules have been prepared.

Electrode preparation, arc melting, and fabrication of the alloys are the immediate objectives of the program.

Development of Niobium-Uranium Alloys

J. A. DeMastry, F. R. Shober, and R. F. Dickerson

Niobium-rich uranium alloys are potential high-temperature reactor fuels; however, little is known concerning their fabrication characteristics and mechanical and physical properties. If these alloys are to be useful as reactor fuels, evaluation of their properties and of the effect of impurities on these properties is necessary. 


$$
\mathrm{F}-8
$$

The effect of impurities is being investigated by using three grades of niobium as base materials in the preparation of alloys: niobium containing less than $0.17 \mathrm{w} / \mathrm{o}$ zirconium and $700 \mathrm{ppm}$ oxygen, niobium containing $0.7 \mathrm{w} / \mathrm{o}$ zirconium and $600 \mathrm{ppm}$ oxygen, and niobium containing less than $100 \mathrm{ppm}$ zirconium and less than $300 \mathrm{ppm}$ oxygen. The alloys of interest are uranium-40,-50,-60,-70,-80, and $-90 \mathrm{w} / \mathrm{o}$ niobium; each of these alloys has been prepared using the three different grades of niobium.

Hot-hardness data have shown that very little softening of these alloys occurs up to at least $900 \mathrm{C}$. The impurities present in the niobium do not seem to affect the hardnesses at elevated temperatures. Differences in hardness at room temperature appear to depend on oxygen content.

Melting and casting have been completed. Eighteen 2-in.-diameter ingots weighing approximately $4 \mathrm{lb}$ each have been prepared by double consumable-electrode arc melting.

Six specimens, two each of uranium-70, -80 , and $-90 \mathrm{w} / \mathrm{o}$ niobium, were sealed in molybdenum packs and hammer forged and rolled at $2550 \mathrm{~F}$ to approximately 0.090in. sheet. This sheet was sheared in the direction of rolling into strips about $1-1 / 2$ in. long and $1 / 2$ in. wide. Hardness measurements made on the alloys before and after fabrication showed an increase in hardness in the hot-worked condition. Metallographic examinations of the hot-worked uranium -80 and $-90 \mathrm{w} / 0$ niobium alloys showed an elongated worked grain structure. The uranium-70 w/o niobium alloy showed an elongated grain structure in which recrystallization and grain growth had been initiated. It appears that $2550 \mathrm{~F}$ is a satisfactory fabrication temperature for the uranium-80 and $-90 \mathrm{w} / \mathrm{o}$ niobium alloys; however, a slightly higher temperature would probably serve better for the uranium $-70 \mathrm{w} / 0$ niobium alloys. Table $F-2$ shows the results of further fabrication of the above-mentioned strips. All of these hot-worked strips of alloy yielded sound sheet when fabricated at 1292 and $1832 \mathrm{~F}$. The sheet obtained was vapor blasted and cut into coupons for corrosion testing.

TABLE F-2. FABRICATION OF URANIUM-NIOBIUM ALLOYS(a)

\begin{tabular}{cccc}
\hline $\begin{array}{c}\text { Nominal Composition } \\
\text { (Balance Uranium), w/o }\end{array}$ & $\begin{array}{c}\text { Temperature of } \\
\text { Fabrication, F }\end{array}$ & $\begin{array}{c}\text { Reduction, } \\
\text { per cent }\end{array}$ & Remarks \\
\hline $90 \mathrm{Nb}($ b) & 75 & 78 & Edge cracking present \\
$90 \mathrm{Nb}(\mathrm{b})$ & 1292 & 72 & Very little edge cracking, sound sheet \\
$90 \mathrm{Nb}(\mathrm{b})$ & 1832 & 75 & -- \\
$80 \mathrm{Nb}($ c) & 75 & 75 & Severe edge cracking \\
$80 \mathrm{Nb}($ c) & 1292 & 72 & No edge cracking, sound sheet \\
$80 \mathrm{Nb}($ c) & 1832 & 75 & No edge cracking, sound sheet \\
$70 \mathrm{Nb}(\mathrm{b})$ & 1292 & 70 & Slight edge cracking, sheet obtained \\
$70 \mathrm{Nb}(\mathrm{b})$ & 1832 & 70 & Slight edge cracking, sheet obtained \\
\hline
\end{tabular}

(a) The materials used in this fabrication study were obtained by shearing strips from the sheet fabricated in molybdenum packs at $2550 \mathrm{~F}$. Results are shown in Table F-2, BMI-1307.

(b) Niobium used contains $700 \mathrm{ppm}$ oxygen and $0.17 \mathrm{w} / \mathrm{o}$ zirconium.

(c) Niobium used contains $600 \mathrm{ppm}$ oxygen and $0.7 \mathrm{w} / \mathrm{o}$ zirconium. 


\section{$\mathrm{F}-9$}

Four molybdenum packs were prepared containing uranium $-40,-50,-60$, and $-70 \mathrm{w} / \mathrm{o}$ niobium. Cover plates $1 / 8 \mathrm{in}$. thick were welded onto these packs. The packs were press forged at $2400 \mathrm{~F}$ from a $3 / 4-$ in. to a $1 / 4$-in. thickness. Asbestos was plaved on the top and bottom of the die to reduce the heat loss during pressing. Each pack was pressed at 700 tons. Table F-3 shows the results obtained. It appears that much higher fabrication temperatures will be necessary for the uranium-40, -50 , $-60 \mathrm{w} / \mathrm{o}$, and $-70 \mathrm{w} / \mathrm{o}$ niobium alloys. Pieces of the above fabricated materials are being examined metallographically to further evaluate the results obtained.

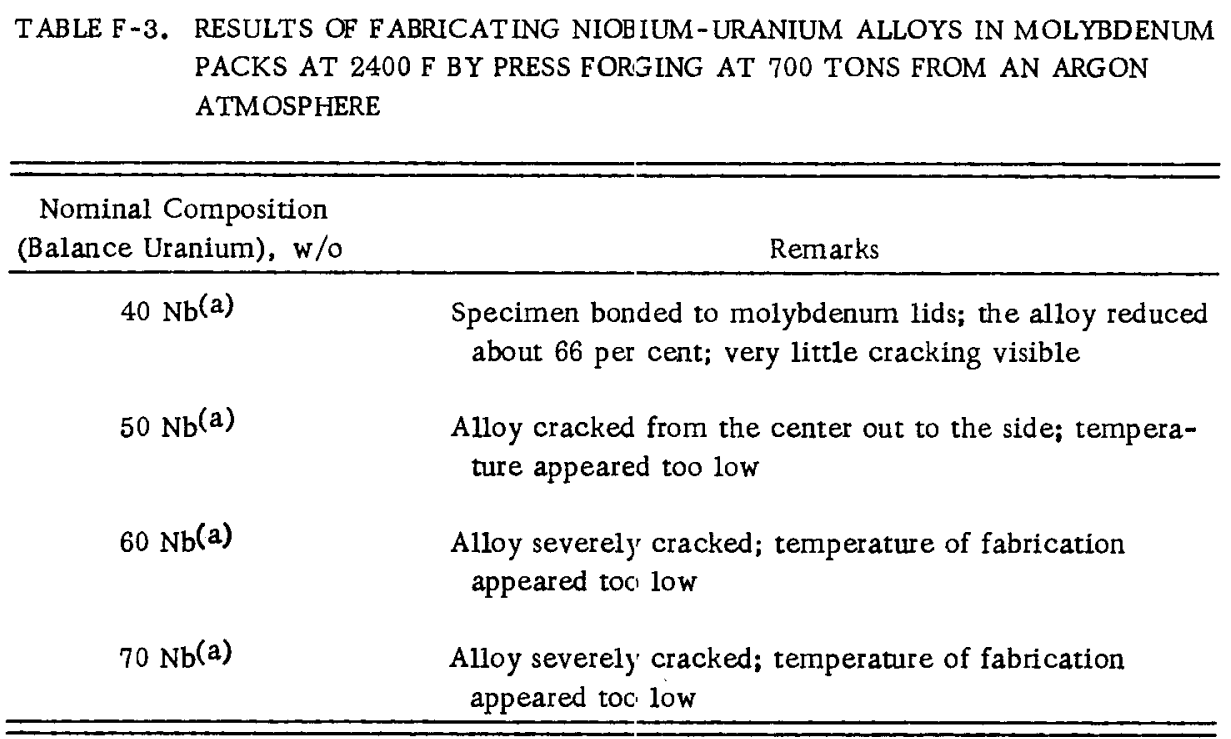

(a) Niobium used contains less than $300 \mathrm{ppm}$ oxygen and less than $100 \mathrm{ppm}$ zirconium.

Three molybdenum packs containing 3-1b 2-in, -diameter ingots of uranium-80 and $-90 \mathrm{w} / \mathrm{o}$ niobium alloys were prepared. These were successfully hammer forged at $2550 \mathrm{~F}$ to sound slabs of material. Table F-4 gives the fabrication results. Specimers for thermal-expansion, electrical-resistivity, and thermal-conductivity measurements are being machined from these slabs. The remaining portions of the slabs are being warm rolled, and sheet tensile specimens are being prepared.

T ABLE F-4. RESULTS OF HAMMER FORGING 2-IN. -DIAMIETER NIOBIUM-URANIUM INGOTS IN MOLYBDENUM PACKS AT 2500 F FROM AN ARGON ATMOSPHERE

\begin{tabular}{ccccc}
\hline $\begin{array}{c}\text { Norninal Composition } \\
\text { (Balaince Uranium), w/o }\end{array}$ & \multicolumn{2}{c}{ Thickness, in. } & Reduction, \\
per cent & Remarks \\
\hline $90 \mathrm{Nb}$ (a) & 2.875 & After F abrication & 80 & Sound material \\
$90 \mathrm{Nb}$ (b) & 1.625 & 0.570 & 71 & Sound material \\
$80 \mathrm{Nb}$ (c) & 2.000 & 0.460 & 72 & $\begin{array}{c}\text { Sound material, slight crack } \\
\text { in center of slab }\end{array}$ \\
\hline
\end{tabular}

(a) Niobium used contains less than 300 ppm oxygen and less than $100 \mathrm{ppm}$ zirconium.

(b) Niobium used contains $700 \mathrm{ppm}$ oxygen and $0.17 \mathrm{w} / \mathrm{o}$ zirconium.

(c) Niobium used contains $600 \mathrm{ppm}$ oxygen and $0.7 \mathrm{w} / \mathrm{o}$ zirconium. 


$$
\text { F-10 }
$$

Results so far indicate that hammer forging of the uranium -80 and $-90 \mathrm{w} / \mathrm{o}$ niobium alloys at $2550 \mathrm{~F}$ is feasible and that forging of the uranium-70 w/o niobium alloy is marginal at $2550 \mathrm{~F}$. Packs are being prepared for fabrication of the remaining uranium -80 and $-90 \mathrm{w} / 0$ niobium alloys.

Further study at higher temperatures is needed before large-scale fabrication of the uranium $-40,-50,-60$, and $-70 \mathrm{w} / \mathrm{o}$ alloys will be possible.

Investigation to see if a ductile-brittle transition temperature exists is continuing; no evidence to support the existence of one has been found as yet.

\section{Development of Thorium-Uranium Alloys}

M. S. Farkas, V. W. Storhok, A. A. Bauer, and R. F. Dickerson

Thorium-uranium alloys are being studied for the purpose of developing improved corrosion resistance and irradiation stability of the alloys by means of alloying and control of processing variables. Ternary and quaternary alloying with molybdenum, niobium, and zirconium is being investigated from the standpoints of strengthening the thorium matrix and of stabilizing the gamma-uranium phase. Also, an attempt is being made to determine effects of a number of variables on uranium particle size and distribution.

Thorium-uranium binary alloys are being studied in the as-cast, hot-rolled, cold-rolled, and swaged conditions in order to determine the variation of structure with fabrication. Recrystallization studies of these alloys are planned also.

Corrosion data in addition to those already reported have been obtained.

Table F-5 summarizes the corrosion rates of some of the ternary and quaternary alloys which performed well. The comparatively low corrosion rates of the alloys when water quenched are attributed to the retention of beta thorium indicated by metallographic examination. X-ray verification of beta-phase retention is being sought. The rapid increase of corrosion rate between $336 \mathrm{hr}$ and $504 \mathrm{hr}$ of test for the thorium-25 w/o uranium $-25 \mathrm{w} / 0$ zirconium alloy is attributed to the transformation of the retained beta thorium. The furnace-cooled thorium $-25 \mathrm{w} / \mathrm{o}$ uranium-25 w/o zirconium specimen is believed to have performed well because of a partial network of zirconiumuranium in the structure which acts as a barrier to corrosion.

TABLE F-5. CORROSION BEHAVIOR OF SEVERAL THORIUM-BASE ALLOYS IN 200 C WATER

\begin{tabular}{lccc}
\hline \multirow{2}{*}{$\begin{array}{c}\text { Nominal Composition } \\
\text { (Balance Thorium), w/0 }\end{array}$} & \multicolumn{4}{c}{ Total Weight Loss at Time Indicated, mg per cm ${ }^{2}$} \\
\cline { 2 - 4 } & $66 \mathrm{Hr}$ & $336 \mathrm{Hr}$ & $504 \mathrm{Hr}$ \\
\hline $25 \mathrm{U}-25 \mathrm{Zr}_{\mathrm{r}}(\mathrm{a})$ & -76.1 & -248.0 & -399 \\
$25 \mathrm{U}-25 \mathrm{Zr}^{(\mathrm{b})}$ & -39.8 & -186.0 & -591.0 \\
$20 \mathrm{U}-20 \mathrm{Zr}^{(\mathrm{b})}$ & -14.0 & -268.0 & -400 \\
$20 \mathrm{U}-20 \mathrm{Zr}-4 \mathrm{Nb}$ (b) & -109.0 & -320.0 & -508 \\
\hline \hline
\end{tabular}

(a) $24 \mathrm{hr}$ at $1000 \mathrm{C}$, furnace cooled.

(b) $24 \mathrm{hr}$ at $1000 \mathrm{C}$, water quenched. 
$F-11$

FISSION-GAS RELEASE FROM REFRACTORY FUELS

J. B. Melehan and F. A. Rough

The objective of this program is to determine the important causes of fission-gas los: from refractory fuel materials, beginning with $\mathrm{UO}_{2}$, and to collect the data needed for a prediction of fission-gas loss from practical fuel materials based on the physical characteristics of the material. The most important cause of fission-gas release from UO $i$ appears to be volume diffusion, since it is at high temperatures that significant relrases of fission gas are encountered. However, all diffusion data so far obtained have not followed diffusion laws strictly, so this assertion has not been adequately confirried. Thus, one of the first objectives of this program is to confirm or disprove the importance of volume diffusion and to show how loss by diffusion is affected by pore structure, by fission-product or defect concentration (that is burnup), and by radiation or in-pile experiments.

In order to confirm or disprove the importance of volume diffusion, initial studies are planned with samples of $\mathrm{UO}_{2}$, having good geometry, to determine whether the rate of lijs of fission gas agrees with that calculated from the external geometry of the sarple and the as sumption of a volume diffusion mechanism. For such an experiment to be meaningful, one must establish the characteristics of the uranium dioxide before the gas-release measurements are made. One must also establish that these pretest characteristics do not change significantly during test.

For initial studies of gas release, a quantity of fused uranium dioxide has been prosured and its characteristics are being studied. It appears to consist of clumps of large single crystals or perhaps pseudo single crystals. These large crystals would be ideal for the type of test proposed, since the presence of grain boundaries, defects, and pore structure would be minimized. Sections could be prepared by petrographic tecliniques to have the desired geometry.

It is expected that in these initial tests of gas release burnups will be kept low enoligh to minimize any changes in characteristics of the crystals. The study of the material to establish evaluation techniques is in progress.

Following these initial tests concerning the validity of volume diffusion, fissiongas release from sintered uranium dioxide will also be studied. Thus, characterization studies of sintered uranium have also begun, and a detailed program intended to proride specifications for the samples for in-pile and out-of-pile gas-release measurements is being planned. It is expected that these studies may also provide a new moclel or models for the mathematical analysis and representation of the gas release frorn sintered $\mathrm{UO}_{2}$.

Considerable experience has already been obtained at Battelle on gas release frorn various fuels. However, the specific problems of instrumenting for the study of gas release from $\mathrm{UO}_{2}$, both in-pile and out-of-pile, are being actively evaluated. The des:gn of in-pile equipment for operation in a beam tube of the Battelle Research Reactcr is in progress. 


\section{$\mathrm{F}-12$ \\ GENERAL FUEL-ELEMENT DEVELOPMENT}

S. J. Paprocki

Cermet fuel materials consisting of from 60 to 90 volume per cent of $\mathrm{UO}_{2}$, $\mathrm{UN}$, or UC dispersed in a stainless steel or niobium matrix are being investigated. These materials have been fabricated by hot press forging, hot swaging, and gas-pressure bonding. Densities exceeding 90 per cent of theoretical have been obtained by all methods. These cermets are far superior to the pure ceramics, possessing higher strength, improved thermal conductivity, and resistance to thermal shock.

The gas-pressure bonding technique is being investigated for cladding and bonding niobium - and molybdenum-base fuel elements and assemblies. The feasibility of bonding these materials by this process has been established. Subscale fuel plates embodying $\mathrm{UO}_{2}$ cores and niobium-coated $\mathrm{UO}_{2}$ cores have been clad with niobium. Although complete grain growth was not obtained along the entire interface, the bonds possessed high strength and could not be separated mechanically.

Dispersion fuels consisting of UN and UC dispersed in stainless steel have been irradiated in the MTR for one and two cycles in an estimated flux of 1.7 by $10^{14}$ (thermal) nv at central core temperatures of from 1325 to $1800 \mathrm{~F}$. The behavior of these materials will be compared with stainless-UO fuels possessing an equivalent uranium235 content that have been irradiated under similar conditions.

An investigation is being conducted with the purpose of obtaining a better understanding of the mechanism of solid-phase bonding under application of heat and pressure. The initial studies have utilized copper couples pressure bonded with variables of time, temperature, and pressure.

\section{Fabrication of Cermet Fuel Elements}

S. J. Paprocki, D. L. Keller, G. W. Cunningham, and D. E. Kizer

Cores with densities 90 per cent or better of theoretical containing 60 to 90 volume per cent ceramic fuel dispersed in a metallic matrix are being prepared by hot press-forging. Fabrication of niobium-coated $\mathrm{UO}_{2}$ powders containing approximately 80 volume per cent $\mathrm{UO}_{2}$ is also being studied. Pressure-bonding techniques are being evaluated as a method of densifying and cladding green-pressed cermets. As cores are being prepared they are being evaluated on the bas is of physical and mechanical properties.

In the work with metallic coated $\mathrm{UO}_{2}$ powders, a powder core containing approximately $80 \mathrm{w} / \circ \mathrm{UO}_{2}$ cold pressed and sintered to a density of $7.14 \mathrm{~g}$ per $\mathrm{cm}^{3}(68$ per cent of theoretical) was pressure bonded at $2250 \mathrm{~F}$ for $4 \mathrm{hr}$ at $10,000 \mathrm{psi}$. The resulting density was $7.62 \mathrm{~g}$ per $\mathrm{cm}^{3}$ or 73 per cent of theoretical. 
F-13.

The relatively low density was thought to be due to poor pack design. Additional cores are being prepared to pressure bond in redesigned packs. Also, green cores of niobium-80 volume per cent $\mathrm{UO}_{2}$ and niobium-80 volume per cent $U N$ were pressure bonded $4 \mathrm{hr}$ at $2250 \mathrm{~F}$ under a pressure of 10,000 psi with resulting densities of 81.4 and $\{4.8$ per cent of theoretical, respectively. The cores were 1 by 1 by $0.040 \mathrm{in}$. prior: to pressure bonding.

Six 1 by 1 by 0.090 -in. green-pressed cores of 80 volume per cent $\mathrm{UO}_{2}$-stainless stee] were pressed and as sembled in a stainless steel frame with 0.125-in. stainless spac 3 rs between each core. Attempts at welding 0.010-in. stainless steel cover plates to the frame were unsuccessful due to the core powder over the frame surface during as se:mbly. A similar frame containing two cores of 80 volume per cent $\mathrm{UO}_{2}$-stainless steel and one of 80 volume per cent UN-stainless steel is being prepared by inserting the cover plate-frame as sembly in a sealed can to eliminate the welding operation.

Electrical-resistivity measurements parallel and perpendicular to the forming direvtion have been made on hot press-forgecl cermets of stainless -74 volume per cent $\mathrm{UO}_{2}$ of 87.5 per cent of theoretical density and molybdenum-80 volume per cent $\mathrm{UO}_{2}$ of 93.6 per cent of theoretical density. The electrical-resistivity values on the stainless steel-matrix cermet were $4250 \mathrm{microhm}-\mathrm{cm}$ parallel with the forming direction and $1070 \mathrm{microhm}-\mathrm{cm}$ perpendicular to the forming direction, while the molybdenummatrix cermet values were 197 and $178 \mathrm{micr} \mathrm{ohm}-\mathrm{cm}$, respectively. Also, the electrical resistivity of a cylindrical 80 volume per cent $\mathrm{UO}_{2}$-stainless steel cermet was measured and found to be $2770 \mathrm{microhm}-\mathrm{cm}$. The measurement was made in a direction parallel with the length. The cylinder was prepared by green pressing the mixture subsequent to pressure bonding $3 \mathrm{hr}$ at $2300 \mathrm{~F}$ at 10,000 psi. The resulting density was 95.5 per cent of theoretical.

Cores of 80 volume per cent $\mathrm{UO}_{2}$-molybdenum were hot press forged at 1900 and $2100 \mathrm{~F}$. Reductions of 30 per cent in thickness were obtained, resulting in densities ranging from 91 to 94 per cent of theoretical. Cores pressed at both temperatures wer $\epsilon$ cracked and broken when removed from the stainless steel hot-press frames.

Green cores of 80 volume per cent UN-stainless steel are being prepared for hot pressing to determine the effect of UN particle sizes in the range of minus 100 to plus $325 \mathrm{mesh}$. In addition, 1 by 1 -in. cores of 80 volume per cent $\mathrm{UO}_{2}$-niobium are being prepared for hot press forging to study the effect of forging temperatures.

Gas-Pressure Bonding of Molybdenum- and Niobium-Clad Fuel Elements

S. J. Paprocki, E. S. Hodge, C. B. Boyer, and R. W. Getz

The gas-pressure bonding technique is being investigated as a process for cladding fuel elements and assemblies with molybdenum and niobium. In gas-pressure bonding, the difficulties encountered in conventional techniques with fuel-element distortion and protective-container ruptures due to dissimilar fabrication characteristics of the protective container are eliminated because only a minimum deformation is needed to obtain solid-s tate bonding. 
In studies of the self-bonding of niobium, to improve the amount of grain growth across the interface between niobium plates and to decrease the amount of contamination at the interface, additional specimens were bonded in Ti-Namel containers for 3 to $4 \mathrm{hr}$ at $2200 \mathrm{~F}$ and $10,000 \mathrm{psi}$. The niobium plate specimens, 0.040 by 1.5 by $1.5 \mathrm{in}$., were bonded with either molybdenum or iron-chromium-aluminum as shim material to separate the specimen from the container. The best bonds were obtained with asreceived niobium that had been pickled in a solution of 95 parts $\mathrm{H}_{2} \mathrm{SO}_{4}$, 4.5 parts $\mathrm{HNO}_{3}$, 0.5 parts $\mathrm{HF}$, and $18.8 \mathrm{~g}$ per liter of $\mathrm{Cr}_{2} \mathrm{O}_{3}$. The pickled niobium was scrubbed in cold Alconox solution and immersed in a bath of saturated sodium hydroxide solution and cold-water rinsed prior to as sembly for bonding. Niobium plates bonded in this manner have been bend tested and the niobium was less ductile after bonding than before bonding. Portions of these specimens have been submitted for chemical analysis in an attempt to determine the cause of the decreased ductility encountered in the bonded specimens.

Four niobium-clad fuel plates were bonded in Ti-Namel containers for 3 to $4 \mathrm{hr}$ at $2200 \mathrm{~F}$ and $10,000 \mathrm{psi}$. Three of the specimens contained l-in.-square uranium dioxide cores 0.040 in. thick. The cores were inserted in niobium picture frames 1.5 in. square and 0.010-in. -thick cover plates were applied. The fourth specimen was fabricated from pieced niobium core receptacles and contained three fuel compartments embodying 0.040-in. -thick cores 1 in. square. The use of pieced compartments to prepare the fuel receptacle offers the twofold advantage of decreased material costs and better dimensional control of the bonding element. Examination of the pieced receptacle after bonding revealed that the components had deformed sufficiently to pro-. duce intimate contact between all of the receptacle components. There were some areas of excellent bonding in all the samples, but grain growth across all of the interfaces was not complete. The bonds were, however, strong, and metallographic examination of the specimens revealed that it appears feasible to bond compartmented receptacles from piece components of niobium.

Several core compositions were used as core inserts for the bonding of the single- and multiple-compartment specimens. Varying the core composition produced no observable effect upon the niobium bonds obtained. The cores utilized in the specimens were uranium dioxide hot pressed, niobium-coated uranium dioxide particles compacted and sintered, niobium-uranium nitride dispersions green compacted, and niobium-uranium dioxide dispersions green compacted. From the results obtained with these core materials, it appears possible to clad ceramics and cermets with niobium. No attempt was made in this study, however, to determine effects of density on the dimensional control on the bonded specimens.

The surface-preparation studies for self-bonding of molybdenum have been continued because satisfactory bonds were not obtained between thin cladding and the thicker frame material during bonding of molybdenum-clad elements. Several specimens with surfaces prepared by different techniques were bonded. Preliminary examination revealed that relatively good bonds were achieved with a $\mathrm{Cr}_{2} \mathrm{O}_{3}$ acid solution. No bonding was observed with a specimen pickled in hydrofluoric acid. Mechanical bonding was obtained with the remainder of the specimens. All of the specimens have been submitted for metallographic examination and bend testing. 
F -15

The as-received molybdenum is extremely brittle and no apparent improvement in dictility has been observed during pressure bonding. The ductility of the molybdenum can be improved by cold rolling. Brittle material has been cold reduced to procluce a more ductile material for the self--bonding studies being conducted on molybdenum.

Additional molybdenum and niobium flat-plate specimens are being prepared to study surface treatments and bonding cycles that will increase the amount of grain grovth across the interface, and improve the ductility of the bonded specimens. Compontents are also being assembled to prepare additional molybdenum- and niobium-clad fuel plates employing pieced core receptacles and ceramic or cermet core inserts.

The Irradiation of UC- and UN-Stainless Steel Dispersion-Type Fuel Elements

A. W. Hare, D. L. Keller, and R. F. Dickerson

The primary purpose of this research is to evaluate the irradiation behavior of dispersion-type fuel elements consisting of uranium carbide or uranium nitride fuel dispersed in a matrix of stainless steel and clad with stainless steel. This irradiation behevior will be compared with that of $\mathrm{UO}_{2}$ dispersion-type fuel elements which were in radiated to comparable levels of burnup. Because of the higher uranium density of UN or UC and consequent lower volume loading, as compared with $\mathrm{UO}_{2}$ dispersion-type elenients of equivalent uranium content, it is expected that these fuel specimens will be nore resistant to radiation damage than $\mathrm{UO}_{2}$-containing specimens.

The test specimens are about $1-1 / 2$ in. long by $11 / 16$ in. wide by 47 mils thick. The stainless steel cladding is approximately 8 mils thick. The fuel is either $24 \mathrm{w} / \mathrm{o}$ UN : n a matrix of stainless steel or $24 \mathrm{w} / 0$ UC in a matrix of stainless steel. Specimens of each type were encapsulated in three temperature-monitored capsules, four specimens, two of each type of fuel, per capsule.

As previously reported, Capsule BMI-18-1 was irradiated in the MTR A-38NE position for two cycles in an estimated flux of $1.7 \times 10^{14}$ (thermal) nv. Capsule BMI18- $i$ was irradiated in the MTR A-38NE position for one cycle in an estimated flux of $1.7 \times 10^{14}$ (thermal) nv. Both capsules have been shipped to Battelle for postirradiation exarnination.

Capsule BMI-18-3 is currently being irradiated in the same MTR reactor position as tire previous capsules.

At this time, a complete analysis of the temperature history of the specimens fronı Capsules BMI-18-1 and BMI-18-2 cannot be made. However, preliminary thermocouple data indicate that the specimens from both capsules operated at central core tem)eratures ranging from about $1325 \mathrm{~F}$ to a maximum of about $1800 \mathrm{~F}$.

Preliminary thermocouple data on Capsule BMI-18-3 indicate that the specimens. are operating at an average central core temperature of about $1460 \mathrm{~F}$. It is planned to irradiate this capsule for four MTR cycles. 


\section{$\mathrm{F}-16$ \\ Factors Affecting Pressure Bonding}

G. W. Cunningham and J. W. Spretnak

An investigation of solid-phase bonding of metals under application of heat and pressure is being conducted to establish the mechanism and kinetics of the process. Most of the specimens prepared to date are 1/2-in. squares of electrolytic tough pitch copper. Bonding is achieved by pressing a $500 \mathrm{rms}$ surface in contact with an $8 \mathrm{rms}$ surface in a standard vacuum-hot-press unit.

Although metallographic examinations of specimens bonded $2 \mathrm{hr}$ at $1460 \mathrm{~F}$ and $10,000 \mathrm{psi}$ do not show the presence of an interfacial boundary, specimens bonded at lower temperatures, e.g., $740 \mathrm{~F}$, contain well-defined interfacial boundaries as well as void areas at the boundaries. The location of the void areas can be related to the original surface shape as follows. Before pressing, a cross-sectional view of the metal-to-metal interface shows a set of $\mathrm{V}$-shaped teeth resting on a flat surface. After partial bonding voids exist at the points where the wide part of the teeth are connected, i.e., the points most remote from the original interface. The interfacial boundary has a shape similar to a sine wave, which indicates that either the teeth are penetrating into the smooth surface or that the smooth surface is being forced in between the teeth.

An interfacial boundary with a similar shape but a smaller amplitude was obtained on a specimen pressed $2 \mathrm{hr}$ at $1100 \mathrm{~F}$ under a pressure of 15,000 psi. Examination with the optical microscope did not reveal any voids in the boundary, but the etched boundary appears to be two to three times thicker than any grain boundary observed. Specimens pressed for $2 \mathrm{hr}$ at $1100 \mathrm{~F}$ at pressures of 5,000 and 10,000 psi as well as a specimen pressed $10 \mathrm{~min}$ at $1100 \mathrm{~F}$ and 10,000 psi are being prepared for metallographic examination.

In order to determine the nature of the interfacial boundary, it seems necessary to establish the mechanism by which the metals are actually placed in contact. The mechanism of simply collapsing holes whether or not diffusion is considered apparently does not apply in the particular model chosen until a large part of the interfacial boundary is formed. The type of boundary should be related to the manner in which it was formed. For example, if sliding of one metal surface past another were to occur, friction might provide enough heat to cause localized melting. For gaining further information on the mechanism, a series of specimens will be pressed at $1100 \mathrm{~F}$ and 10,000 psi for periods of time ranging from a few minutes to several hours.

Specimens of high-purity nickel and crystal-bar zirconium are being prepared for additional bonding studies. 


\title{
G-1 \\ G. FATIGUE STUDIES OF' INCONEL AND INOR-8
}

\author{
R. G. Ciarlson
}

Fatigue Studies of Inconel

This program has as its objectives obtaining basic fatigue information and establishing quantitative relationships among the variables of temperature, stress, strain, time, and cyclic frequency for Inconel. The current phase of the program is concerned witk measuring and recording strain associated with the cyclic portion of a combined loac.

During January, stress-cycling tests were continued on Inconel specimens at 1301) $\mathrm{F}$ and at $1500 \mathrm{~F}$, cycled at $1 \mathrm{cps}$. Continuous stress and strain traces were made during all tests. All tests were conducted at lifetimes of less than 100,000 cycles.

Analysis of the data for the tests at $1500 \mathrm{~F}$ showed that the shape of stress-strain hysieresis curves varies throughout the entire lifetime of the specimen. A plot of plastic strain per cycle against cycles where plastic strain was considered to be the widlh of the hysteresis curve at zero stress showed that the plastic strain was very large initially but within the first 1000 cycles decreased to a minimum value. The plastic strain then increased approximately at a linear rate until a few thousand cycles befcre failure. Plastic strain then increased rapidly to failure. The slope of the linear portion of the curve was found to vary directly with stress.

A log-log plot of the average plastic strain per cycle against specimen lifetime proluced a curve with a negative slope which is approximately linear, but apparently has a small negative change in slope with increasing specimen lifetimes.

Preliminary examination of the data for the tests at $1300 \mathrm{~F}$ indicated specimen behavior similar to that for the specimens evaluated at $1500 \mathrm{~F}$. At the lower temperature, a greater number of cycles was required before the plastic strain reached its minimum value. Also, the slope of the linear portion of the strain curve is apparently less at the lower temperature. For a given average plastic strain, the specimen lifetim obtained at $1300 \mathrm{~F}$ was greater than at $1500 \mathrm{~F}$.

During February, tests on Inconel will be continued at $1 \mathrm{cps}$ and, in addition, tests will be initiated at $0.1 \mathrm{cps}(6 \mathrm{cpm})$.

\section{Fatigue Studies of INOR-8}

This program is concerned with the investigation of temperature and frequency dependence of fatigue properties of INOR-8 alloy.

During January, rotating-beam fatigue tests of INOR-8 were performed at $1500 \mathrm{~F}$, cycled at $100 \mathrm{rpm}$ and $3000 \mathrm{rpm}$. In addition, tests were started at $1100 \mathrm{~F}$ and $100 \mathrm{rpm}$. The data obtained to date for the studies at $1500 \mathrm{~F}$ indicate that there is an 


$$
\mathrm{G}-2
$$

effect of frequency on specimen lifetime. Specimens cycled at $3000 \mathrm{rpm}$ showed an increase in lifetimes on the order of magnitude of 10 to 1 over specimens cycled at $100 \mathrm{rpm}$. Additional fatigue tests are being made to verify this conclusion.

During February, tests will be continued to obtain data for cyclic frequencies of 100 and $3000 \mathrm{rpm}$ at temperatures of 1100 and $1500 \mathrm{~F}$. 
$\mathrm{H}-1$

\section{H. PHYSICAL RESEARCH}

F. A. Rough

Studies of uranium compounds and the mechanism of thermal migration of hydrogen in zirconium are in progress for the USAEC Research Division.

In the uranium-compound work, sintered uranium monocarbide compacts are being prepared for irradiation and subsequent meassurement of gas release.

In the research on thermal migration of hydrogen in zirconium, new data on the diffusion coefficients of hydrogen in beta zirconium have been obtained. These data are part of the information to be used in theoretical analyses of actual thermal migration experiments.

Preparation and Properties of Refractory Uranium Compounds

A. B. Tripler, Jr., M. J. Snyder, and W. H. Duckworth

Sintered compacts of uranium monocarbide are being prepared in which bulk density: porosity, and grain size are varied by varying initial particle size, compacting pressure, temperature of sintering, and time at temperature. The sintered compacts will be exposed to short-time low temperature low-level irradiation in the BRR. A correlation will be sought between the physical properties listed above and fissionprocuct release caused by laboratory heat treatment.

Two UC powders of different average particle sizes are being used in the fabrication of compacts 5/16 in. in diameter by 1-1/4 in. long. The average particle size is 1.4. $7 \mu$ for the coarse powder and $6.2 \mu$ for the fine powder.

To obtain sound hydrostatically compacted specimens from the coarse powder requires the use of a small amount of binder. Although none is required for the fine powder, the binder is being used in preparing all specimens to avoid introducing an additionil variable. Five milliliters of a $3 \mathrm{w} / 0$ solution of Carbowax 4000 is used for each specimen.

Metallographic sections of compacts fabricated from powders of different particle sizes show that the grain size, after sintering at $1600 \mathrm{C}$ for $\mathrm{l} \mathrm{hr}$, varies with the initial particle size. Quantitative measurements of grain size and estimation of the amount of porcisity by metallographic means, as well as bulk density measurements, will be made.

The UC series of compacts should be completed or nearly completed during the next bimonthly period. Work on UN will then commence. 
$\mathrm{H}-2$

Thermal Migration of Hydrogen in Zirconium

J. W. Droege, W. M. Albrecht, W. D. Goode, and H. H. Krause

Construction of the apparatus for the experimental study of hydrogen migration in zirconium hydride under the influence of a thermal gradient is under way. Diffusion coefficients for hydrogen in beta zirconium are being obtained from permeation-rate measurements.

Thermal Diffusion

The various components of the system designed for this study are being assembled and built. Specimens of beta-phase zirconium hydride have been prepared. The thermal-diffusion cell will consist of a cylindrical section of zirconium hydride, separated on each side by thin stainless steel from copper blocks. The two faces of the zirconium hydride will be maintained at different temperatures and the copper will provide a uniform temperature across each face of the disk. This assembly is to be pressure bonded in a stainless steel shell. The measurement of hydrogen pressure on both sides of the disk will be facilitated by holes drilled through the copper blocks. The vacuum system to which the thermal-diffusion cell will be connected is in the process of construction.

\section{Diffusion Coefficients}

Present experiments consist of the measurement of the amounts of hydrogen permeating a zirconium disk. Predetermined hydrogen pressures are maintained on both sides of the disk so that a relatively small concentration gradient is established across the sample.

Diffusion coefficients for hydrogen in beta zirconium are determined by both the time-lag and the steady-state methods. The time-lag method, developed by Barrer*, is based on the time-lag, L, related to the time to establish the steady state in which the concentration gradient across the permeation membrane remains constant. The diffusion coefficient is calculated from the relationship,

$$
\mathrm{D}=\ell^{2} / 6 \mathrm{~L},
$$

where $l$ is the thickness of the permeation membrane and $D$ is the diffusion coefficient. It is seen that the diffusion coefficient depends only upon the thickness of the sample and the time lag.

The steady-state method is based upon the solution of Ficks** first law of diffusion for the permeation process at steady state. Crank*** gives a solution of the general form

\footnotetext{
* Barrer, R. M., Trans. Faraday Soc., 36, 1235 (1940).

Fick, A., Ann. Phys. hpz. , 170, 59 (1855).

* Crank, J., The Mathematics of Diffusion, Oxford University Press, London (1956), p 42.
} 


$$
D=F l / A\left(c_{1}-c_{2}\right) \text {, }
$$

whe::e

$F=$ linear permeation rate at steady state

$A=$ surface area of one face of the disk:

$c_{1}=$ hydrogen concentration on the upstream surface of the disk determined by the pressure, $P_{1}$, and temperature of the sample

$c_{2}=$ hydrogen concentration on the dowristream surface of the disk determined by the pressure, $\mathrm{P}_{2}$, and temperature of the sample.

It is noted that this determination is dependent upon the dimensions of the sample and the lydrogen concentrations on the surfaces. Barrer* discusses the possibility that the iffective surface concentrations are not those determined from equilibria studies. The surface concentrations, $c_{1}$ and $c_{2}$, are calculated from equilibrium data reported by Eills and McQuillan**. Agreement between the diffusion coefficients obtained by the time-lag method, which is independent of corcentration, and the steady-state method would indicate that the surface concentrations are essentially those obtained at static equilibrium.

Zirconium disks used in initial experiments became contaminated. These samples had gray to blue-black surface films and vacuum-fusion analysis showed that considerable oxygen had been picked up. This contamination was essentially prevented whell the apparatus was evacuated for $16 \mathrm{hr}$ cr longer at pressures in the range of $10^{-t} \mathrm{~mm}$ of mercury before starting the experiments. With this precaution, samples remained bright and shiny after six experimental runs. Vacuum-fusion analysis indicated that very little oxygen had been picked up during the experiment.

Diffusion coefficients for hydrogen in beta zirconium have been determined in the temperature range 650 to $850 \mathrm{C}$. Two iodide zirconium disks having a surface area of $1.25 \mathrm{~cm}^{2}$ on a face and thicknesses of 0.063 and $0.065 \mathrm{~cm}$ were used in the determination:s. For each experiment, the average hydrogen concentration of the sample was varied in the range 15.2 to 32 a/o. The time-lag could not be determined in all the experiments. In some cases, diffusion was so rapid that the values of $\mathrm{L}$ were too small to $b$ : measured accurately. In other cases, it was difficult to maintain the desired presisure difference at the surfaces of the disk during the initial portion of the experiment. This made it impossible to apply the time-lag method, although the linear rate established later in the experiment yielded valid data.

The experimental conditions and diffusion coefficients are summarized in Table $1-1$. The agreement between the diffusion coefficients obtained by the two methods is within the limits of experimental error. This indicates that the use of static equilibrium concentrations in the steady-state method is justified.

\footnotetext{
*Barrer, R. M., Diffusion in and Through Solids, Cambridge Unj.versity Press, London (1951), pp 181 and 182.

Ells, C. E., and MoQuillan, A. D., J. Inst. Metals, 85, 89 (1756).
} 
TABLE H-1. SUMMARY OF RESULTS FROM DETERMINATION OF THE DIFFUSION COEFFICIENTS FOR HYDROGEN IN BETA ZIRCONIUM

\begin{tabular}{|c|c|c|c|c|c|}
\hline \multirow{2}{*}{$\begin{array}{l}\text { Temperature, } \\
\text { C }\end{array}$} & \multirow{2}{*}{$\begin{array}{l}\text { Average Hydrogen } \\
\text { Concentration, a/o }\end{array}$} & \multicolumn{2}{|c|}{$\begin{array}{c}\text { Pressures on Membrane, } \\
\text { mm of mercury }\end{array}$} & \multicolumn{2}{|c|}{ Diffusion Coefficient, $10^{-7} \mathrm{~cm}^{2}$ per sec } \\
\hline & & $\overline{P_{1}}$ & $\mathrm{P}_{2}$ & From Steady State & From Time Lag \\
\hline 650 & 23 & 0.9 & 0.4 & 6.0 & 4.5 \\
\hline 650 & 32 & 1.5 & 0.7 & 4.7 & -- \\
\hline 700 & 17.5 & 1.4 & 0.8 & 30 & 31 \\
\hline 700 & 31.5 & 4.5 & 1.4 & 22 & 28 \\
\hline 750 & 15.2 & 2.3 & 1.5 & 130 & $\cdots$ \\
\hline 750 & 29.2 & 7.9 & 4.5 & 96 & 95 \\
\hline 800 & 20.1 & 8.4 & 5.2 & 310 & -- \\
\hline 800 & 27.8 & 14.5 & 10.4 & 210 & 330 \\
\hline 850 & 30.3 & 31.1 & 29.9 & 900 & -- \\
\hline
\end{tabular}

The diffusion coefficients determined by the steady-state method [Equation (H-2)] were plotted against reciprocal temperature. The equation for the temperature dependence of the diffusion coefficient, as determined by the least-squares method, is

$$
\log D=(-11310 \pm 340) / T(K)+(6.02 \pm 0.34) \text {, }
$$

and the activation energy for the diffusion process is $51.8 \pm 1.6 \mathrm{kcal}$ per $\mathrm{g}$ atom. From a plot of the data and Equation $(\mathrm{H}-3)$ the diffusion coefficients determined at different concentrations are in good agreement, although a trend toward slower diffusion with increasing hydrogen concentration may be indicated. Further experiments are planned to spot check the diffusion coefficients obtained to date using disks of different thickness than those previously used.

A study of the diffusion of hydrogen in delta zirconium (zirconium hydride) is being initiated. The primary purpose of this study is to determine the effect of hydrogen concentration on the diffusion process. 


\section{I-1}

\section{SOLID HOMOGENEOUS FUELED REACTORS}

W. H. Goldthwaite

An evaluation of 1-1/2-in.-diameter spherical fueled graphite fuel elements is in progress. The results of the first static capsule irradiation of three types of fueled spheres, as reported below, indicate that their mechanical integrity was not impaired by $j$ rradiation at surface temperatures of about $1300 \mathrm{~F}$ to burnups of $1-1 / 2$ per cent of the 4-1/2.g of contained uranium-235. On the basis of these encouraging albeit preliminary results, primary attention has been directed to obtaining more quantitative information of fission-gas release. Low-level irradiations followed by laboratory heating in a helium gas stream and high-level irradiations with simultaneous fissiongas collection and analysis are planned and discussed below.

Postirradiation Evaluation of Spherical Fueled-Graphite Specimens

R. J. Burian and J. E. Gates

The testing phases of the postirradiation examination of three pairs of fueledgraphite spheres irradiated in Capsule SP-1 have been completed. Each pair of spheres was supplied by a different vendor and the fuel was incorporated in them by different methods. One pair of spheres was fabricated by the National Carbon Company, by pressing a powdered mixture of $2301 \mathrm{graphite}$ filler, pitch binder, and $\mathrm{UO}_{2}$ intc the required shape and baking to set the binder. A second pair of specimens was prepared at Battelle by pressing powdered $\mathrm{UO}_{2}$, carbon filler, and resin binder into spheres of about 1 in. in diameter and cladding them with a 1/4-in. -thick shell of resin-bonded AGOT graphite. These spheres were baked at $2000 \mathrm{~F}$ to set the binder. The third pair of spheres was supplied by Sylvania-Corning. These spheres were mashined from extruded AGOT graphite and fueled by soaking in a uranyl-nitrate solutior.. The spheres were then roasted to convert the nitrate to $\mathrm{UO}_{2}$. The fuel loading of the six spheres was between 4.31 and $4.71 \mathrm{~g}$ of 93 per cent enriched uranium.

The six 1.5-in. -diameter spheres were canned in pairs for irradiation. The three cans containing the spheres were encased in one capsule and irradiated in the $B R \Omega$ at temperatures near $1300 \mathrm{~F}$. The capsule was irradiated for three reactor cycles of 2 weeks each. It was removed with an estimated burnup of 1.5 to 1.9 per cent of the uranium-235 on December 1, 1958.

The inner cans were removed from the capsule by sawing off the ends with a powrer hacksaw and slitting the capsule body with a metal slitting saw powered by a renctely operated milling machine. During the slitting operation, the capsule slipped in the vise and the slitting saw cut the skin of the can containing the two spheres fabricated by BMI. After completion of the slitting operation, the two halves of the outer capsule shell were pulled apart, freeing the inner cans.

The three inner cans were recovered and examined. Detailed examination of the can containing the Battelle-fabricated spheres revealed that the slitting saw had 
penetrated the skin allowing entrapped fission gas to escape. The other cans appeared undamaged. These two cans were punctured in a sealed and evacuated system and the contained gases collected and sampled for fission gas. A leak, later confirmed by mass-spectrometer measurements, occurred in the vacuum system during the collection of the gases from the can containing the spheres fabricated by National Carbon. The gas contained in the third can which contained Sylvania-Corning fabricated spheres was successfully collected. After the fission-gas collection was completed the cans were opened and the specimens recovered.

Each can was opened by slitting the sides and ends with the metal slitting saw. The spheres were recovered along with the graphite flour used to fill the annulus around them. The flour poured easily and no packing or caking was noted. The neutron dosimeter wires in each can were also recovered and they and the flour were stored. Photographic records were made of representative and unique areas of the cans and capsule body.

The spheres were visually inspected at magnifications to $32 \mathrm{X}$. Only one specimen, Battelle Specimen 12, was found to be damaged. A crack was noted extending approximately $120 \mathrm{deg}$ along a great circle of the sphere. The crack appeared to exist only in the cladding. All the specimens were then photographed, measured, and weighed. The pre- and postirradiation diameters and weights are compared in Tables I-l and I-2, respectively. Five of the six spheres were then abrasion tested.

Because of the crack in Battelle Specimen 12, it was not abrasion tested. The other five specimens were tested for abrasion resistance. Each pair of spheres except those fabricated by BMI was tumbled in a small container simultaneously with ten unirradiated dummy spheres as the abrasion test. The dummy spheres were fabricated by National Carbon in the same manner as their two irradiated specimens, except that they were fueled with natural $\mathrm{UO}_{2}$. Battelle Specimen 11 was abraded by eleven dummy spheres. All postirradiation abrasion tests were $10 \mathrm{~min}$ in duration. The weight changes for tests performed on the control and the irradiated specimens are compared in Table I-3. Before the specimens were weighed, efforts were made to remove all loose dust clinging to the spheres. The weight gain of Specimens E-13, 86, and 87 during testing has no significance. It probably is the result of dust collected and driven into the specimens during testing coupled with a surface which lost little or no material itself. After weighing, one specimen of each pair, including the unabraded sphere fabricated by BMI, was compression tested. The one Battelle specimen that was abraded and the remaining specimen of each pair were impact tested.

The cracked Battelle sphere was selected for compression testing because it was felt that the damaged cladding would have little effect on the results of this test if the plane of the crack were oriented transverse to the axis of loading during the test. National Carbon Specimen 86, which contained two thermocouple holes, was also selected for this test and was oriented in a similiar manner. Sylvania-Corning Specimen E-16, was selected for the compression test at random. At least one unirradiated control specimen of each type was also tested. The results of these tests are presented in Table I-4.

The impact tests were performed on Specimens 11, E-13, and 87, fabricated by BMI, Sylvania-Corning, and National Carbon Company, respectively. The test involved dropping a constant weight from various heights onto the specimen being tested. The 
TABLE I-1. COMPARISON OF DIAMETER MEASUREMENTS OF FUELED-GRAPHITE SPHERES BEFORE AND AFTER IRRADIATION

\begin{tabular}{|c|c|c|c|c|c|}
\hline \multirow[b]{2}{*}{ Specinen } & \multirow[b]{2}{*}{ Fabricator } & \multicolumn{3}{|c|}{ Diameter Across Flats, in. } & \multirow{2}{*}{$\begin{array}{c}\text { Decrease in Diameter, } \\
\text { per cent }\end{array}$} \\
\hline & & Preirradiation & Postirradiation & Change & \\
\hline \multirow[t]{3}{*}{11} & BMI & 1.4578 & 1.4530 & -0.0048 & 0.33 \\
\hline & & 1.4546 & 1.4508 & -0.0038 & 0.26 \\
\hline & & 1.4532 & 1.4492 & -0.0040 & 0.28 \\
\hline \multirow[t]{3}{*}{12} & BMI & 1.4530 & 1.4516 & $=0.0014$ & 0.10 \\
\hline & & 1.4525 & 1.4484 & -0.0041 & 0.28 \\
\hline & & 1.4530 & 1.4507 & -0.0023 & 0.16 \\
\hline \multirow[t]{3}{*}{$E-13$} & Sylvania-Corning & 1.4832 & 1.4705 & -0.0127 & 0.86 \\
\hline & & 1.4801 & 1.4678 & -0.0123 & 0.83 \\
\hline & & 1.4830 & 1.4667 & -0.0163 & 1.10 \\
\hline \multirow[t]{3}{*}{$E-16$} & Sylvania-Corning & 1.4808 & 1.4673 & -0.0135 & 0.91 \\
\hline & & 1.4822 & 1.4662 & -0.0160 & 1.08 \\
\hline & & 1.4810 & 1.4689 & -0.0121 & 0.82 \\
\hline \multirow[t]{3}{*}{86} & National Carbon & 1.4934 & 1.4923 & -0.0011 & 0.07 \\
\hline & & 1.4901 & 1.4865 & -0.0036 & 0.24 \\
\hline & & 1.4877 & 1.4835 & -0.0042 & 0.28 \\
\hline \multirow[t]{3}{*}{87} & National Carbon & 1.4911 & 1.4868 & -0.0043 & 0.29 \\
\hline & & 1.4905 & 1.4870 & -0.0035 & 0.23 \\
\hline & & 1.4852 & 1.4821 & $=0.003 i$ & 0.21 \\
\hline
\end{tabular}

TABLE I-2. COMPARISON OF WEIGHTS OF FUELED-GRAPHITE SPHERES BEFORE AND AFTER IRRADIATION

\begin{tabular}{|c|c|c|c|c|c|}
\hline \multirow[b]{2}{*}{ Specinnen } & \multirow[b]{2}{*}{ Fabricator } & \multicolumn{3}{|c|}{ Weight, $g$} & \multirow{2}{*}{$\begin{array}{c}\text { Weight Change, } \\
\text { per cent }\end{array}$} \\
\hline & & Before Irradiation & After Irradiation & Change & \\
\hline 11. & BMI & 40.0555 & 38.3543 & -1.7012 & -4.25 \\
\hline $1:$ & BMI & 39.2485 & 38.9592 & -0.2893 & -0.71 \\
\hline$E-13$ & Sylvania-Corning & 52.7694 & 50.4056 & -2.3638 & -4.48 \\
\hline$E-16$ & Sylvania-Corning & 52.8046 & 51.2862 & -1.5184 & -2.88 \\
\hline 86 & National Carbon(a) & 52.1154 & 52.1300 & +0.0146 & +0.03 \\
\hline $8 r_{i}$ & National Carbon & 51.9042 & 51.8628 & -0.0414 & -0.08 \\
\hline
\end{tabular}

(a) Sjecimen 86 contained two drilled holes for thermocouples. Although care was taken to remove loose graphite flour from the holes before postirradiation weight measurements were taken, it is possible that some remained. 
TABLE I-3. COMPARISON OF WEIGHT LOSSES OF CONTROL AND IRRADIATED FUELED-GRAPHITE SPHERES AFTER ABRASION TESTS

\begin{tabular}{|c|c|c|c|c|c|c|c|}
\hline \multirow[b]{2}{*}{ Specimen } & \multirow[b]{2}{*}{ Fabricator } & \multirow[b]{2}{*}{ Condition } & \multirow{2}{*}{$\begin{array}{c}\text { Type of } \\
\text { Fuel Used }\end{array}$} & \multicolumn{4}{|c|}{$\begin{array}{l}\text { Total Weight Loss During } \\
\text { Indicated Test }(a), g\end{array}$} \\
\hline & & & & $10 \mathrm{Min}$ & $\mathrm{A}$ & $\mathrm{B}$ & $\mathrm{C}$ \\
\hline $9(b)$ & BMI & Control & Enriched & $-\infty$ & 4.0844 & - & $\cdots$ \\
\hline $10(b)$ & BMI & Control & Enriched & - & 4.8001 & $-\infty$ & -- \\
\hline$A=1$ & Sylvania-Corning & Control & Naturai & $\infty$ & 0.0059 & 0.0137 & 0.0069 \\
\hline$A-4$ & Sylvania-Corning & Control & Natural & - & 0.0219 & 0.0069 & 0.0120 \\
\hline$E-4$ & Sylvania-Corning & Control & Enriched & $\cdots$ & 0.0333 & $\cdots$ & $m$ \\
\hline$E-8$ & Sylvania-Corning & Control & Enirhced & $\cdots$ & 0.0352 & $\cdots$ & $\cdots$ \\
\hline 58 & National Carbon & Control & Natural & -- & 0.0050 & 0.0010 & 0.0003 \\
\hline 60 & National Carbon & Control & Natural & $\cdots$ & 0.0042 & 0.0027 & 0.0082 \\
\hline 82 & National Carbqgn & Control & Enriched & $-\infty$ & 0.0195 & $\cdots$ & $\rightarrow$ \\
\hline 89 & National Carbon & Control & Enriched & -- & 0.0281 & -- & $\infty$ \\
\hline 11 & BMI & Irradiated & Enriched & 0.0187 & $\cdots$ & - & -- \\
\hline 12 & BMI & Irradiated & Enriched & (c) & $-\infty$ & - & $-\infty$ \\
\hline$E-13$ & Sylvania-Corning & Irradiated & Enriched & 0.0029 (d) & $\cdots$ & $\cdots$ & -- \\
\hline$E-16$ & Sylvania-Corning & Irradiated & Enriched & 0.0008 & $-\infty$ & $-\infty$ & $\infty$ \\
\hline 86 & National Carbon & Irradiated & Enriched & $0.0026^{(d)}$ & $-\infty$ & $\cdots$ & - \\
\hline 87 & National Carbon & Irradiated & Enriched & $0.0024(d)$ & $\cdots$ & $\ldots$ & $\ldots$ \\
\hline
\end{tabular}

(a) Tests A, B, and C were three consecutive tests of $2 \mathrm{hr}$ in duration each. The ball mill for the 10-min test operated at $48 \mathrm{rpm}$. For Tests A, B, and C it operated at $52 \mathrm{rpm}$.

(b) Specimens had surface cracks prior to testing.

(c) Not tested because of crack in cladding.

(d) This value is a gain in weight rather than a loss. This is presumed to be due to dust driven into the surface during testing. 
TABLE I-4. RESULTS OF COMPRESSION TESTS ON CONTROL AND IRRADIATED FUELED-GRAPHITE SPHERES

\begin{tabular}{|c|c|c|c|c|c|}
\hline Specimen & Fabricator & Condition & Ultimate Load, lb & $\begin{array}{c}\text { Apparent Maximum } \\
\text { Deflection }^{(a)} \\
\text { in. }\end{array}$ & $\begin{array}{l}\text { Load } \\
\text { Modulus }(\mathrm{b}) \\
\text { lb per in. }\end{array}$ \\
\hline 21 & BMI & Control & 1060 & 0.0240 & 43,500 \\
\hline$E-4:$ & Sylvania-Corning & Control & 2555 & 0.1024 & 24,900 \\
\hline 60 & National Carbon & Control & 2410 & 0.0433 & 55,900 \\
\hline $8{ }^{\varsigma}$ & National Carbon & Control & 2865 & 0.0508 & 56,400 \\
\hline $1: !$ & BMI & Irradiated & 258 & 0.0321 & $8,300(c)$ \\
\hline$E-i 6$ & Sylvania-Corning & Irradiated & 2672 & 0.0679 & 39,100 \\
\hline $86 i$ & National Carbon & Irradiated & 3712 & 0.0556 & $65,800(d)$ \\
\hline
\end{tabular}

(a) Based on assumed straight line load-deflection relationship.

(b) Slope of straight line portion of load-deflection curve.

(c) The cladding on this specimen was cracked.

(d) I'wo thermocouple holes were drilled in this specimen. 
weight (hammer) weighed 6-1/4 lb and could be dropped from any height up to 25 in. The tests were conducted by continuously dropping the hammer from increasing heights until the specimen exhibited some type of failure. The results of the tests on the irradiated specimens are compared with the results of similar tests on unirradiated control specimens in Table I-5.

Measurement of the krypton-85 activity in the gas samples is prevented at the present time by the more abundant amount of xenon-133 activity. The gas samples are being stored to allow decay of the xenon activity. However, calculations based on the xenon-133 activity indicate that only 0.005 per cent of the xenon-133 theoretically pres ent in the two Sylvania-Corning specimens at the time of gas collection had escaped from the specimens. There are two immediately discernible possibilities that may have resulted in the apparent small gas release. The calculations were based on the xenon radioisotope whose half-life and other constants are in dispute. This may introduce an uncertainty as large as 50 per cent into the resultant gas-release figures. A more probable cause of the apparent small gas release is adsorption of the gases by the powered graphite surrounding the sphere. Graphite is known as a good adsorber for xenon and krypton even at room temperature. The trace amounts of gas involved here might be efficiently adsorbed by the graphite.

The postirradiation tests did not exactly duplicate the preirradiation tests. However, the abrasion resistance of the Sylvania-Corning and National Carbon specimens appears to be unchanged or to be improved slightly after irradiation. Because of the large weight loss of the Battelle specimens tested prior to irradiation and the relatively short duration of the postirradiation test, no irradiation-induced changes can be defined. The data derived from the impact tests indicate a trend toward a reduction in impact strength in all types of specimens as a result of irradiation. The results of the compression tests indicate a trend toward an increase in strength of the irradiated Sylvania-Corning and the National Carbon specimens. Similiar effects have been noted after neutron irradiation at lower temperatures. Evaluation of the data obtained from the impact and compression tests is difficult because of the limited number of tests performed, and because of the lack of information about the direction of loading in relation to the graphite cell configuration of the specimens. Consequently, definite conclusions cannot be made but rather only apparent trends can be pointed out.

All hot-cell phases of these examinations have been completed. The dosimeters, graphite flour, core samples, and specimens have been stored awaiting a decision as to their disposition.

Encapsulation and Ir radiation

G. E. Raines and W. H. Goldthwaite

During January the major emphasis of this research was shifted to determination of fission-product-release behavior. The capsule design for a previous static irradiation of the fueled-graphite spheres (SP-1) has been revised to provide for the continuous removal and analysis of released fission gases. Two pairs of the spherical specimens will be irradiated in a capsule very similar to the first one which was employed to study irradiation damage. Separate helium-flow paths will be provided 
I-7

TABLE I-5. RESULTS OF IMPACT TESTS ON CONTROL AND IRRADIATED FUELED-GRAPHITE SPECIMENS

\begin{tabular}{|c|c|c|c|c|}
\hline Specimen & Fabricator & Condition(ia) & $\begin{array}{c}\text { Energy Required to } \\
\text { Cause Failure, } \\
\text { ft-lb }\end{array}$ & $\begin{array}{c}\text { Number of Drops } \\
\text { Performed During } \\
\text { Test(b) }\end{array}$ \\
\hline $2 \epsilon$ & BMI & Control & $3.12(\mathrm{c})$ & 1 \\
\hline $2 \xi$ & BMI & Control & 2.08 & 2 . \\
\hline$E-i$ & Sylvania-Corning & Control & 12.5 & 12 \\
\hline$E-14$ & Sylvania-Corning & Control & 11.5 & 11 \\
\hline 16 & National Carbon & Control & 11.5 & 11 \\
\hline $8 \varepsilon$ & National Carbon & Control & 11.5 & 11 \\
\hline 11 & BMI & Irradiated & $1.04^{(\mathrm{c})}$ & 1 \\
\hline$E-13$ & SylvaniamCorning & Irradiated & 10.4 & 12 \\
\hline 87 & National Carbon & Irradiated & 8.35 & 10 \\
\hline
\end{tabular}

(a) Battelle Specimens 25 and 28 contained natural $\mathrm{UO}_{2}$; all others contained enriched $\mathrm{UO}_{2}$.

(b) Drops were normally, but not always, made at increments of 2-in. heights with a 6-1/4-1b hammer.

(c) Since the first drop caused failure, this energy value may be larger than the minimum energy which would have caused the sliecimen to fracture. 
through each pair of specimens, with less than 100 psi required to give an adequate flow through the graphite powder surrounding the specimens.

Flow rates will be selected to minimize travel time from the specimens to the sampling device ( 3-5 sec) so that information may be obtained concerning shorthalf-life products. Both direct sampling of the passing gas and adsorption on activated charcoal will be employed.

Quantitative data will be sought with a more elaborate scheme for adsorbing the xenon and krypton fission gases on activated charcoal and then utilizing a gamma-ray spectrometer for analysis. Fairly long trapping time will be employed to obtain samples of sufficient activity for accurate determinations. Both sampling in a charcoal trap designed to fit in the well of the spectrometer and sampling by a larger trap from which the adsorbed gases will be transferred to an ampoule for analysis will be employed.

Irradiation of the first of the se gas-flow capsules at a $1500 \mathrm{~F}$ specimen temperature is scheduled to start in February with a duplicate capsule to follow in March.

The heating and gas-sampling system has been constructed. A test ball containing natural uranium oxide in graphite has been irradiated and heating will begin shortly. This preliminary run is necessary to determine the characteristics of the system, such as order of magnitude of the gas release, extent of other materials released from the ball during heating, the efficiency of the trapping system, and optimum flow rate of carrier gas.

Following the preliminary run, enriched balls will be irradiated and subjected to postir radiation heating.

$\frac{\text { Measurements of Fission-Gas Release }}{\frac{\text { During Postirradiation Heating of }}{\text { Fueled-Graphite Balls }}}$

R. Lieberman, D. N. Sunderman, and M. Pobereskin

A series of experiments consisting of postirradiation heating of fueled-graphite balls and the measurement of released fission gases will be performed.

Four balls of different composition or mode of manufacture will be irradiated for $1 \mathrm{~min}$ at a flux of about $10^{12} \mathrm{nv}$ in the BRR. The time of irradiation was chosen to minimize temperature rise and to allow the formation of sufficient xenon-133 so that one part in 10,000 of that present in a single ball is measurable.

Following irradiation and a period of several days to allow decay of the $21-\mathrm{hr}$ iodine-133 precursor, the balls will be heated, individually, while in a helium stream. The helium will pass through a series of traps to collect the xenon-133 which will be sampled intermittently for analysis. The temperature of heating will cover the range between room temperature and $1600 \mathrm{~F}$ with major emphasis on the 1000 to $1600 \mathrm{~F}$ 


\section{I-9 and $I-10$}

region. Time of heating will depend upon the rate of xenon-133 evolution, but is expecited to cover several days per ball.

The primary objective of this series of experiments will be to obtain relative fission-gas relase rates for the several types of balls. The release-rate information will be analyzed to determine whether diffusion rates or activation energies can be obti:ined from it. Due to the heterogeneity of the fuel material, it may be impossible to assign values to the diffusion rates or activation energies, but an attempt will be macle to formulate a mechanism for fission-gas release which is consistent with the known variables of internal structure and composition. 
$\theta$

$\theta$
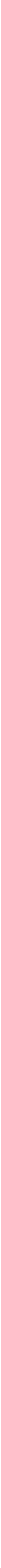
$\mathrm{J}-1$

\section{J. CORROSION PROBLEMS ASSOCIATED WITH THE}

RECOVERY OF SPENT REACTOR FUEL ELEMENTS

C. L. Peterson, P. D. Miller, C. M. Stewart, J. D. Jackson, R. E. Sharpe, W. C. Baytos, T. E. Snoddy, and F. W. Fink

The evaluation of materials of construction for use in the Darex, Sulfex-Thorex, Zirflex, and Fluoride-Volatility processes of: nuclear fuel recovery has been continued. Locialized attack has occurred on specimens of Types 304 ELC and 347 stainless steel expc sed to chloride-contaminated fission-product-recovery solutions, but no stresscorrosion cracking has been observed after $576 \mathrm{hr}$. Heat treatments of Ni-o-nel to improve its resistance to Thorex solutions are still under investigation. Only Haynes 21 has shown relatively low corrosion rates during scouting experiments with $Z$ irflex decladding solution. Corrosion has been showr to be directly dependent on temperature in the $\mathrm{NaF}-\mathrm{LiF}-\mathrm{ZrF}_{4}$ system.

The Darex Process

The Darex process is proposed for the recovery of uranium from fuel elements containing stainless steel as a diluent or cladding. Dissolution is accomplished in dilute aqua regia. Following this, the chlorides are stripped from the solution, which is then so adjusted that the uranium may be recovered by conventional methods of solvent extraction.

$\underline{\text { Dissolver Studies With Titanium }}$

Titanium steam tubes are being exposed to Initial and Beginning Darex solutions. No further examination of the steam tube from the Middle Darex solution has been completed.

Fiss ion-Product-Recovery Solutions

Specimens of Type 304 ELC and 347 stainless steel have been exposed to boiling $3 \mathrm{M} \mathrm{HNO}_{3}$ containing $60 \mathrm{~g}$ per liter of dissolved stainless steel and $800 \mathrm{ppm} \mathrm{Cl}^{-}$. Examinations and solution changes have been made after $72,240,408$, and $576 \mathrm{hr}$. No stress-corrosion cracking has been observedl thus far. Intergranular attack occurred on the surfaces of the Type 304 ELC specimens with roughening of the weld and some pitting of the cut edges. Corrosion rates as high as 4.2 mils per month were calculated from over-all weight losses. Intergranular attack was seen only in the heat-affected arec.s along the weldments on the Type 347 specimens. Again, some pitting was observed on the cut edges and some perforation of the weldments has occurred. Sectioning of a Type 347 specimen following $408 \mathrm{hr}$ showed that the intergranular attack had only penetrated about one grain deep at that time. Additional studies with chloride-free solutions and solutions containing $400 \mathrm{ppm} \mathrm{Cl}$. are now in progress to determine if the chloride is responsible for the pitting and intergranular attack. 
$\mathrm{J}-2$

The Sulfex-Thorex Process

Stainless-clad fuel elements of thorium or thoria could be dejacketed by dissolution in sulfuric acid. The thorium or thoria would then be dissolved by a solution of 13.0 $\mathrm{M} \mathrm{HNO}_{3}, 0.05 \mathrm{M} \mathrm{F}^{-}$containing an addition of aluminum to mitigate corrosion. The final Thorex solution would be about $8.5 \mathrm{M} \mathrm{HNO}_{3}, 0.05 \mathrm{M} \mathrm{F}^{-}, 1.0 \mathrm{M} \mathrm{Th}\left(\mathrm{NO}_{3}\right)_{4}$ and contain, in addition, any aluminum that may have been introduced at the start.

Experiments With Carpenter $20 \mathrm{Cb}$

Materials are being assembled to construct a bench-scale dissolver from Carpenter $20 \mathrm{Cb}$. Actual Sulfex-Thorex dissolutions of Consolidated Edison fuel pins will be carried out in this dissolver and in a like dissolver constructed from Ni-o-nel.

Experiments With $\mathrm{Ni}-\mathrm{O}-\mathrm{nel}$

Ni-o-nel specimens welded with parent metal strips and with No. 65 wire have been exposed for $755 \mathrm{hr}$ to boiling Initial Thorex solution containing $0.20 \mathrm{M} \mathrm{Al}^{+3}$. These specimens were heat treated for $0.5 \mathrm{hr}$ at $1850 \mathrm{~F}$ and air quenched prior to welding. The corrosion rates have been relatively low, in the neighborhood of 1 mil per month, but have shown a tendency to increase slightly after the first $288 \mathrm{hr}$. General attack was evident over the surfaces, while intergranular attack occurred in the heataffected areas along the weldments.

The optimum heat treatment found so far has been at $1850 \mathrm{~F}$ after welding. Other heat treatments for longer periods at 1850 and $1950 \mathrm{~F}$ are in the process of being investigated.

Present flowsheet conditions will not permit the use of $0.2 \mathrm{M} \mathrm{Al}^{+3}$ additions without complications arising in the Thorex process. Three intermediate additions of 0.04 , 0.09 , and $0.15 \mathrm{M} \mathrm{Al}^{+3}$ to Initial Thorex solutions were scouted with unwelded, stabilized $\mathrm{Ni}-\mathrm{o}-\mathrm{nel}$ specimens to determine the minimum addition necessary to control corrosion. A smooth curve could be constructed from these data which showed that at least $0.10 \mathrm{M} \mathrm{Al}^{+3}$ is necessary to keep the corrosion rate below 5 mils per month. The corrosion rates increase sharply as the concentration of aluminum is lowered. Ultimately, the minimum aluminum addition necessary to mitigate corrosion must be chosen with due regard to the duration in which the conditions of the Initial Thorex solution will prevail in the dissolver, as it appears that corrosion will become much less severe as the solution builds up in thorium and decreases in free nitric acid.

Scouting Experiments With Other Metals

Scouting experiments in Sulfex and Thorex solutions will be made soon with specimens of D 319 L stainless steel and with niobium-stabilized Illium 98. 
$\mathrm{J}-3$

The Zirflex Process

Chemical decladding of Zircaloy-2-clad uranium fuel elements by boiling $6 \mathrm{M}$ $\mathrm{NH}_{4} \mathrm{~F}, 1 \mathrm{M} \mathrm{NH} \mathrm{NO}_{3}$ solutions, followed by core dissolution in $10 \mathrm{M} \mathrm{HNO}_{3}$ containing 0.0 ! $\mathrm{M} \mathrm{HF}$ and small amounts of zirconium and aluminum as contaminants, is a procedure proposed for the Zirflex process.

Scouting experiments conducted thus far have shown that only Haynes 21 gives corjosion rates below 4 mils per month in the decladding solution. Type $309 \mathrm{Cb}$ stainless steel and Carpenter $20 \mathrm{Cb}$ gave rates in the 8 to 10 -mils-per-month range, while Ni-ci-nel, Haynes 25, Types 347, 316, and 3104 ELC stainless steels, and Hastelloy F gave: rates ranging upward from 10 to $20 \mathrm{mils}$ per month. All of the se materials have shovn rates from 4 to 10 mils per month in the nitric acid solutions containing the fluo: ide contamination. Intergranular and other types of localized attack have been prevalent on many of these specimens.

Other materials to be scouted in the near future include D $319 \mathrm{~L}$ stainless steel and one or two Illium alloys.

A 24-hr scouting study was made in which stabilized, unwelded Ni-o-nel coupons wex? exposed to boiling $5 \mathrm{M} \mathrm{HF}$. High rates of $87 \mathrm{mils}$ per month in the vapor, 49 at the interface, and 40 in the liquid were recorded. The attack, in this case, was very unifirm.

\section{The Fluoride-Volatility Process}

Evaluation of various alloys for construction of the hydrofluorinator in the fluo:ride-volatility process has continued. An HF sparge through a bath of molten fluoride salts would be used to remove zirconiun from fuel elements.

A series of runs has been completed in one of the low-melting compositions of the sodium-lithium-zirconium fluoride syste:ms. This composition is $19.3 \mathrm{NaF}, 25.6$ $\mathrm{LiF}, 54.9 \mathrm{ZrF}_{4}$, and $0.21 \mathrm{UF}_{4}$ (mole per cent). Corrosion was evaluated at an HF flow of 11) $\mathrm{g}$ per $\mathrm{hr}$ at 600,650 , and $700 \mathrm{C}$. Table J-1 shows the penetration values obtained for : an exposure of about $200 \mathrm{hr}$ at each temperature. It can be seen that, as might be expected, the corrosion increased rapidly with an increase in temperature. Some increcised corrosion was noted at the interface areas during the $700 \mathrm{C}$ experiment. In nearly every case, INOR-1 has resistance equal to or better than INOR-8.

A comparison of these data with those reported earlier for the starting salt composition $43 \mathrm{NaF}-57 \mathrm{LiF}$ shows that the starting salt is much more corrosive than the fina! salt.

Plans are now being made for studying the effect of dissolution conditions on the corrosion. Slugs of Zircaloy-2 will be dissolved continuously in contact with the melt container and metal specimens to evaluate possible protective galvanic effects that might be furnished. 


$$
\mathrm{J}-4
$$

TABLE J-1. CORROSION OF INOR-1 AND INOR-8 AT VARIOUS TEMPERATURES IN A FINAL NaF-LiF- $\mathrm{ZrF}_{4} \mathrm{SALT}^{(\mathrm{a})}$

\begin{tabular}{|c|c|c|c|c|c|}
\hline \multirow[b]{2}{*}{ Specimen } & \multirow[b]{2}{*}{ Type } & \multirow[b]{2}{*}{ Position } & \multicolumn{3}{|c|}{ Corrosion Rate, mils per month } \\
\hline & & & $600 \mathrm{C}, 200 \mathrm{Hr}$ & $650 \mathrm{C}, 200 \mathrm{Hr}$ & $700 \mathrm{C}, 160 \mathrm{Hr}$ \\
\hline INOR-1 & Coupon & Vapor & 0.24 & 0.56 & 1.3 \\
\hline INOR-8 & Coupon & Vapor & 0.43 & 1.2 & 2.4 \\
\hline INOR-1 & Coupon & Interface & 0.76 & 3.3 & 13. \\
\hline INOR-8 & Coupon & Interface & 1.0 & 4.6 & 13. \\
\hline INOR-1 & Coupon & Liquid & 1.7 & 4.4 & 11. \\
\hline INOR-8 & Coupon & Liquid & 2.5 & 4.2 & 15. \\
\hline INOR-1 & Tube & Liquid-impingement & 0.61 & 0.23 & 0.36 \\
\hline INOR-8 & Tube & Liquid-impingement & 0.74 & 0.63 & 1.1 \\
\hline
\end{tabular}

(a) $19.3 \mathrm{NaF}, 25.6 \mathrm{LiF}, 54.9 \mathrm{ZrF}_{4}$, and $0.21 \mathrm{UF}_{4}$ (mole per cent); $10 \mathrm{~g}$ per hr HF. 
$\mathrm{K}-\mathrm{l}$.

\section{K. DEVELOPMENTS FOR SRE, OMRE, AND OMR}

J. E. Gates and F. A. Rough

The objectives of this research for Atcmics International are to develop uranium morocarbide as a fuel for the SRE and to perform postirradiation studies of materials of interest to the SRE, OMRE, and OMR programs.

\section{EVALUATION OF URANIUM MONOCARBIDE \\ AS A REACTOR FUEL}

F. A. Rough

Uranium carbide containing $5 \mathrm{w} / \mathrm{o}$ carbon is being studied as a fuel for the Sodium Reactor Experiment (SRE). At the moment, too few data are available for an evaluation, but results from specimens having burnups up to $1420 \mathrm{MWD} / \mathrm{T}$ and maximum center temperatures up to $1600 \mathrm{~F}$ have been encouraging. Five additional capsules of sperimens are to be examined over a period of several months. Examination of the next capsule, which has been irradiated to about $5000 \mathrm{MWD} / \mathrm{T}$, is due to begin in February.

Irradiation of Uranium Monocarbide

D. Stahl, J. H. Stang, and W. H. Goldthwaite

Three capsules of uranium monocarbide specimens have already been irradiated, one at the BRR and two at the MTR. The second capsule irradiated at the MTR, BMI23-i., was removed from the A28NE position in the MTR after Cycle 115 for a total irradiation of six cycles. It is being returned to the Battelle Hot Cell Facility and is scheduled to arrive in February. Capsule BMI-23-3, which was returned to Battelle for :hermocouple repairs, was inserted into the A28NE position for Cycle 116 and will be irradiated for four cycles. The irradiation of Capsule BMI-23-4 is continuing in A27,5E.

Typical temperature data recorded for these capsules during January are somewha: below the $1500 \mathrm{~F}$ design level. It may be necessary to lower Capsules BMI-23-3 and BMI-23-4, which are operating at center-line temperatures from about 1200 to $1350 \mathrm{~F}$, a few inches during Cycle 116 shutdown (February 2) to bring them into a higher flux zone.

Capsule BMI-23-5 (containing uranium-4.6 w/o carbon) has been loaded and shipped to the MTR, and it is scheduled for insertion into the A27SE position when $\mathrm{BMI}-23-4$ is removed (during Cycle 118 shutdown). The loading and final assembly of Capsule BMI-23-6 (containing uranium-4.8 w/o carbon) has begun, and it should arrive at the MTR during the latter part of February. 
Postirradiation Examination of Uranium Monocarbide

S. Alfant, A. W. Hare, F. A. Rough, and R. F. Dickerson

The primary objective of this program is to study the changes in the physical and chemical properties of uranium monocarbide caused by irradiation in a test reactor.

A capsule containing 12 UC specimens was irradiated at the BRR, and six capsules, each containing two specimens, were fabricated and assembled for irradiation at the MTR. Capsule BMI-23-1 has been discharged from the MTR, and examination of specimens taken from this capsule and from the BRR capsule are in the process of being completed. Capsule BMI-23-2, with an estimated burnup of $5000 \mathrm{MWD} / \mathrm{T}$, also has been discharged from the MTR and has been shipped to the Battelle Hot-Cell Facility. Examination of the samples in this capsule is expected to begin during February.

During the past month, metallographic examination was performed on specimens taken from the BRR capsule and from Capsule BMI-23-1. This metallographic examination of specimens having up to $1420 \mathrm{MWD} / \mathrm{T}$ burnup indicated no evidences of radiation damage or changes in structure. Some cracks were evident in the structure but were attributed to the etchant that was used and to the possible reaction of UC in moist air. It is planned to provide storage in a desiccator to eliminate this surface cracking. Burnup analyses on specimens taken from Capsule BMI-23-1 and the BRR capsule are expected to be completed in the near future.

\section{POSTIRRADIATION STUDIES OF SRE, OMRE, AND OMR FUEL MATERIALS}

J. E. Gates

Metallography and measurements of the coefficient of linear expansion of irradiated thorium-11 w/o uranium specimens have been completed. These specimens were irradiated in Capsule Trains NAA-15-6 and NAA-15-7.

Three OMR and three OMRE-type fuel plates have been received for examination. The burnup of the fuel in each plate will be determined and sections of the plate will be examined metallographically.

OMR Fuel Plates

D. K. Dieterly

Three OMR-type fuel plates have been received for examination. These plates are 12.1 in. long by 2.4 in. wide by 0.470 in. thick. The 0.100 -in. -thick core of uranium $-3.5 \mathrm{w} / 0$ molybdenum is clad with aluminum. The cladding was fabricated 
$\mathrm{K}-3$

into deep fins to aid in heat dissipation. These plates were part of a complete fuel elemer.t irradiated recently in the OMRE. The element was disassembled and the three plates were shipped to Battelle.

It is planned to measure the relative intensity of the gamma radiation emitted frorn each plate by scanning with a gamma-ray spectrometer. Each of the plates will be sectioned and specimens removed from each plate for burnup analyses. Six specimerss will be analyzed. In addition, two sections will be prepared for metallographic exanination.

This examination is now in progress.

OMRE Fuel Elements

D. K. Dieterly

Three OMRE-type fuel plates have been received for examination. These plates are part of an OMRE fuel element that was recently removed from the OMRE. The fuel plates are $38.5 \mathrm{in}$. long by $2.7 \mathrm{in.}$ wide by $0.030 \mathrm{in}$. thick. The core is composed of $25 \mathrm{w} / \circ \mathrm{UO}_{2}$ dispersed in Type 304 stainless steel. The 5-mil-thick cladding is of Type 304 stainless steel. These plates will be examined in the same manner as was desiribed for the OMR plates.

This examination is scheduled to begin in February.

SRE Fuel Materials

G. E. Lamale, D. M. Cheney, and A. A. Bauer

Thorium-Uranium Specimens

The postirradiation examination of twelve specimens of thorium-11 w/o uranium alloy has been completed. These specimens were irradiated in $\mathrm{NaK}$ to burnups ranging fror 0.57 to 1.5 total a/o at temperatures near $1200 \mathrm{~F}$. All specimens were initially $0.3 \% 5$ in. in diameter by $1.4 \mathrm{in}$. long, and were prepared with 93 per cent enriched uranium by cold swaging. The specimens were irradiated in the MTR in two capsule traiis, NAA-15-6 and NAA-15-7. The data obtained from all phases of the examination havi: been reported except for metallography and measurements of the linear expansion coefficients.

Measurements of the linear expansion coefficients have been completed and the data are being evaluated. Measurements were made on two irradiated specimens and two controls. A complete discussion of these measurements will be included in the next monthly report. 
Five specimens of the thorium-1 $1 \mathrm{w} / \mathrm{o}$ uranium alloy and a section of the stainless steel thermal shield from one capsule have been examined metallographically. The fueled specimens are listed in Table $\mathrm{K}-1$.

TABLE K -1 . THORIUM-11 w/O URANIUM METALLOGRAPHIC SPECIMENS

\begin{tabular}{|c|c|c|c|c|c|}
\hline Capsule & Specimen & $\begin{array}{l}\text { Burnup } \\
\text { total a } \\
\end{array}$ & $\begin{array}{c}\text { Irradiation } \\
\text { Temperature }^{(b)} \text {, } \\
\end{array}$ & $\begin{array}{c}\text { Decrease in } \\
\text { Specimen } \\
\text { Density, } \\
\text { per cent }\end{array}$ & Location of Metallographic Section \\
\hline \multirow[t]{2}{*}{ NAA $-15-6$} & $15-6-3$ & 1.3 & 1090 & 1.4 & Middle of relatively undamaged specimen \\
\hline & $15-6-5(c)$ & 1.5 & 1100 & 2.4 & $\begin{array}{l}\text { Swollen end of specimen opposite thermo- } \\
\text { couple hole }\end{array}$ \\
\hline \multirow[t]{3}{*}{$N A A-15-7$} & $15-7-A^{(c)}$ & 0.72 & 1130 & 7.1 & $\begin{array}{l}\text { Badly swollen end of specimen opposite } \\
\text { thermocouple hole }\end{array}$ \\
\hline & $15-7-D$ & 0.66 & 1200 & 4.0 & Eroded section from thermocoupled end \\
\hline & $15-7-E$ & 0.63 & 1200 & 4.4 & Middle of relatively undamaged specimen \\
\hline
\end{tabular}

(a) Determined by correlating radiochemically determined burnups with dosimeter data.

(b) Reported by A tomics International.

(c) These sections were lost during preparation.

The fuel specimens were ground through 600-grit SiC paper using kerosene as a lubricant. Polishing was performed on Syntron vibrating polishers using $1-\mu$ alumina, Linde $A$, and Linde $B$, on microcloth with kerosene as a lubricant. The sections were then etched electrolytically in a solution of 2 per cent $\mathrm{H}_{2} \mathrm{SO}_{4}$ in lactic acid at $20 \mathrm{v}$ dc. This procedure outlined the alpha-uranium and thorium oxides but did not bring out the grain boundaries. Techniques tried on unirradiated material with the same fabrication history as the irradiated specimens indicated that chemical or electrolytic etchants were unsatisfactory. Only cathodic etching produced visible grain boundaries. The inability to chemically etch this material was apparently the result of the cold-worked structure produced during fabrication by cold swaging.

The section cut from Specimens 15-6-5 and 15-7-A were inadvertently ground through and lost during metallographic preparation. Observations of these samples prior to their loss indicated that the microstructures were in general similar to those of the remaining specimens, with the exception of much larger void areas.

Specimen 15-7-E exhibited no localized damage after irradiation although the density decreased considerably. A section near the middle of the specimens was examined and large voids were observed in the microstructure near the center of this section. The voids were generally as sociated with uranium particles, and probably the grain boundaries since the uranium is generally found there. In other areas, the uranium particle size was observed to be smaller but still associated with voids. The thorium appeared to be badly contaminated with oxides. Cracks were observed extending through the numerous oxide stringers. These cracks may have been formed during fabrication and were probably accentuated during irradiation. Since these cracks represent potential sources of failure in this fuel material, it would seem advisable to reduce the number of oxide inclusions by improving the quality of the alloying materials. Evidence of defects peculiar to casting were also found in this specimen, 
$\mathrm{K}-5$ and $\mathrm{K}-6$

possibly indicating the need for improvement in casting techniques. Such evidence generally consisted of large voids surrounded by oxides. This particular specimen may have been prepared from the top of a cast ingot since large clumps of oxides were not as evident in the other specimens that were examined.

The structure of the section removed from Specimen 15-7-D was more uniform than that of Specimen 15-7-E. This section was removed from an eroded area near the thermocoupled end of the specimen. The uranium particles were small and uniformly dispersed. Small voids were associated with the uranium particles. Examination of the microstructure adjacent to the eroded area indicated that eithe $r$ melting or pla:; tic deformation had occurred. Voids were more pronounced here than in other areas although the uranium particle size and distribution did not appear to change.

A section from the center of Specimen 15-6-3 was examined. This specimen exhibited no localized damage after irradiation. The microstructure of this specimen resembled the others. Uranium particles were evenly dispersed and of small size. Voids were associated with the particles and some cracks were observed in the matrix.

Examination of the microstructure of the specimens indicates that the fission gas reliased from the uranium particles produces voids adjacent to these particles. It appears that the voids are propagated along grain boundaries. This probably resulted in the excessive swelling of the specimens. Cracks were observed associated with oxille particles and are viewed as potential sources of failure. It would therefore be advantageous to use more pure grades of alloying materials.

The stainless steel thermal shield from around Specimen 15-7-D was also examined metallographically. A section was removed from the shield at a point opposite the eroded area on this specimen. A macroscopic examination indicated the presence of a ring of corrosive or other attack on the inside of the shield at this point. Evidence of this ring as such could not be found microscopically although the inner surface showed uniform intergranular corrosive attack. The grain boundaries near the inner surface were thickened and the surface was very rough. Evidences of intergranular corrosion were found as deep as $0.006 \mathrm{in}$. below the inner surface of the shield. 
$\theta$

$\vartheta$ 
L - 1

\title{
L. TANTALUM AND TANTALUM-ALLOY STUDIES
}

\author{
J. H. Stang
}

Study of tantalum-tungsten-alloy materials is continuing. Emphasis during January was on the preparation and mechanical-property testing of annealed specimens. Strip samples of the se materials are nearly ready to be sent to Los Alamos Scientific Labjratory for plutonium-alloy corrosion exposures. This will be the second batch of tantalum-tungsten samples forwarded to Los Alamos, the first being fabricated from colc-rolled stock. Tantalum alloyed with carbon, rhenium, and yttrium is now being arc melted.

\section{Development of Container Materials for LAMPRE Applications}

\author{
D. C. Drennen, M. E. Langston, C. J. Slunder,
} and J. G. Iunleavy

Ten specimens of tantalum and tantalum-1.5 to $6.0 \mathrm{w} / \mathrm{o}$ tungsten in the annealed ( $2 \mathrm{he}$ at $2600 \mathrm{~F}$, in vacuo) condition have been prepared for shipment to LASL for plutonium-alloy compatibility testing. Currently, hardness, grain size, and chemical composition of control samples are being determined. Information available from studies of microstructure indicates that the various materials are sound. There is no evidence of grain-boundary phases that would suggest an appreciable degree of contamination.

The room-temperature tensile properties of tantalum and tantalum-tungsten specimens in the annealed condition are given in Table $L-1$. As might be expected, the data show that the yield and ultimate tensile strengths increase substantially with the additions of tungsten. The strength of the $6 \mathrm{w} / \mathrm{o}$ tungsten alloy is about twice that of unalloyed tantalum. Conversely, its ductility is decreased to about one-half the value of uralloyed tantalum. The reason for the low ductility values for unalloyed tantalum specimens is not known; this material was expected to show at least 50 per cent elongation in the annealed condition. The differences in tensile properties among the three specimens at each of the four tungsten contents (nominally $0,1.5,3$, and $6 \mathrm{w} / \mathrm{o}$ ) may have been caused by unintentional contamination introduced during arc melting and subsequent fabrication. An attempt will be made to correlate these results with the analyses for carbon, hydrogen, nitrogen, and oxygen.

Three new series of tantalum alloys are being prepared by arc melting in helium: (1) tantalum-1.5, -3.0 , and $-6.0 \mathrm{w} / 0$ rhenium, (2) tantalum $-0.25,-0.50$, and -1.0 $\mathrm{w} / \mathrm{o}$ yttrium, and (3) tantalum $-0.25,-0.50$, and $-1.0 \mathrm{w} / \mathrm{o}$ carbon. Button specimens will be processed according to the procedure established for the tantalum-tungsten allors. 


\section{$\mathrm{L}-2$}

TABLE L-1. ROOM-TEMPERATURE TENSILE PROPERTIES OF ARC-MELTED UNALLOYED TANTALUM AND NOMINAL TANTALUM-1.5 TO 6.0 w/O TUNGSTEN ALLOYS AFTER VACUUM ANNEALING

Cold Rolled, 0.030-In. - Thick Strip

Annealed $2 \mathrm{Hr}$ at $2600 \mathrm{~F}$ in Vacuo

\begin{tabular}{|c|c|c|c|}
\hline $\begin{array}{c}\text { Composition, } \\
\text { w/o }\end{array}$ & $\begin{array}{l}\text { 0.2 Per Cent Offset } \\
\text { Yield Strength, } \\
10^{3} \mathrm{psi}\end{array}$ & $\begin{array}{c}\text { Ultimate } \\
\text { Tensile Strength, } \\
10^{3} \mathrm{psi}\end{array}$ & $\begin{array}{l}\text { Elongation } \\
\text { in } 1 \mathrm{In} ., \\
\text { per cent }\end{array}$ \\
\hline Unalloyed $\mathrm{Ta}$ & 30.5 & 38.2 & 44 \\
\hline Unalloyed $\mathbf{T a}$ & 22.8 & 34.0 & 35 \\
\hline Unalloyed $\mathrm{Ta}$ & 24.7 & 33.7 & 30 \\
\hline $\mathrm{Ta}-1.0 \mathrm{~W}$ & 38.1 & 48.0 & 24 \\
\hline $\mathrm{Ta}-1.71 \mathrm{~W}$ & 34.6 & 47.0 & 35 \\
\hline $\mathrm{Ta}-1.46 \mathrm{~W}$ & 31.5 & 45.0 & 44 \\
\hline $\mathrm{Ta}-1.45 \mathrm{~W}$ & 27.1 & 41.8 & 38 \\
\hline $\mathrm{Ta}-2.92 \mathrm{~W}$ & 43.4 & 54.8 & 29 \\
\hline $\mathrm{Ta}-2.71 \mathrm{~W}$ & 36.8 & 50.5 & 38.5 \\
\hline Ta-2.94 W & 36.4 & 51.0 & 37 \\
\hline Ta-6.23 W & 63.1 & 74.8 & 23 \\
\hline $\mathrm{Ta}-5.80 \mathrm{~W}$ & 69.1 & 79.5 & 20 \\
\hline $\mathrm{Ta}-6.06 \mathrm{~W}$ & 59.7 & 71.0 & 15 \\
\hline
\end{tabular}




\section{$\mathrm{L}-3$ and $\mathrm{L}-4$ \\ $\underline{\text { Irradiation Damage of Tantalum }}$}

E. J. Jablonowski, F. R. Shober, F. A. Rough, and $R$. F. Dickerson

Activity on this program will be resumed upon receipt of tantalum stock (for capsule-irradiation specimens) from Los Alamos. 
0

-
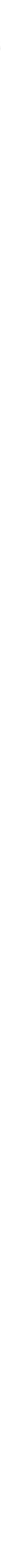
M- 1

\title{
M. DEVELOPMENTAL STUDIES FOR THE PWR
}

\author{
R. W. Dayton
}

Studies have been begun of a modified baffling arrangement designed to improve mixir.g in the lower plenum of the PWR model. Preliminary results indicate satisfactory beharior.

Further studies of the pressure bonding of plate-type oxide fuel plates have shown that weak bonds of as-bonded plates have been caused by graphite trapped between Zircéloy-2 surfaces being bonded. Avoiding the smearing by buffing the graphite cores, or beta treatment after bonding, seems to elirninate the difficulty in the tests which have so far been made.

\section{Reactor Flow Studies}

L. J. Flanigan and H. R. Hazard

Air-flow studies in a quarter-scale model of the PWR are being conducted at Battelle to determine the effects of lower-plenum geometry on mixing and flow distribution in Core 2. Previous work includes development of an optimum baffling arrangement for the 7.5-ft core design and construction of a quarter-scale model of a similar design suitaisle for incorporation into the prototype.

In January, the baffling arrangement was installed in the model and flow studies startis. Results thus far indicate that the performance of the prototype design is satisfactory.

In February, the flow studies will be completed, and a final report covering the studies will be prepared.

Pressure Bonding of Zircaloy-2-Clad Fuel Elements Containing Compartmented Oxide Fuel Plates

S. J. Paprocki, E. S. Hodge, D. C. Carmichael, and P. J. Gripshover

A compartmentalized flat-plate Zircaloy-2-clad fuel element containing uranium dioxile cores is being considered for PWR Core 2. An investigation is being conducted to dei:ermine the feasibility of producing these elements by gas-pressure bonding. In this technique, the fuel elements are assembled from belt-abraded strip components, edge welded, evacuated, and sealed to form a gastight assembly which is then pressure bonded at $1550 \mathrm{~F}$ and 10,000 psi for $4 \mathrm{hr}$ in a helium atmosphere. One half of each element is being heat treated in an $1850 \mathrm{~F}$ salt bath for $5 \mathrm{~min}$ subsequent to pressure bonding. The uranium dioxide fuel is graphite coated by a spray technique to minimize reaction with the $\mathrm{Zircaloy}-2$ cladding. 
Corrosion testing in $680 \mathrm{~F}$ water has continued on the intentionally defected compartments of eight small specimens prepared by pressure bonding at $1550 \mathrm{~F}$ or $1750 \mathrm{~F}$ with or without an additional heat treatment at $1850 \mathrm{~F}$ for $5 \mathrm{~min}$. Although these elements contain zones of oxygen-rich Zircaloy- 2 adjacent to the $\mathrm{UO}_{2}$ cores, there has been no significant growth in corrosion for exposure times up to 56 days.

A number of 0.150 by 4.3 by 15.0 in. specimens have been prepared by bonding at $1550 \mathrm{~F}$ for $4 \mathrm{hr}$ at $10,000 \mathrm{psi}$. It has been found that helium entrapped within the element during edge welding of the fuel plate prior to pressure bonding produced small voids and incomplete bonding along the bond interface of pressure-bonded specimens. For this reason, it was necessary to evacuate these elements after edge welding. Evacuation was accomplished through a narrow projection machined on one end of the element. Two methods have been used for the evacuation and sealing of these elements. In one method, the element is placed inside a chamber which is evacuated and the final hole is sealed by melting the end of the projection with an induction coil contained within the chamber. In the second method, the projection of the element is connected to a vacuum manifold and, while the specimen is being evacuated, the projection is sealed by resistance-upset welding. Both methods have yielded leaktight seals and adequately evacuated elements, as evidenced by the disappearance of the small voids along the bond interface.

As many as 20 compartments of each specimen have been defected and subjected to alternate intercompartmental leak testing (700 psi of internal pressure) and corrosion testing. No intercompartmental leaks have been detected in these tests and no significant growth has been observed in corrosion for up to 35 days of exposure in $680 \mathrm{~F}$ water.

Results of the burst tests conducted on the se elements reveal that, although many of the as-bonded specimens burst in a normal manner at pressures up to 4300 psi with deflections of $14 \mathrm{mils}$, a number of the as-bonded elements developed intercompartmental leaks at elevated pressures. These leaks usually resulted from the separation of the cover plates from the longitudinal rib at internal pressures in excess of 2000 psi. The conclusion drawn from these results is that there is no leakage path in the bonded specimens before pressure testing; however, the bond interface is contaminated and is weak as a result of the lack of sufficient grain growth. In burst tests of the beta-treated elements, only 2 specimens out of 35 tested have exhibited intercompartmental leaks. In one specimen, the re was leakage between two compartments while the other specimen contained several defective compartments. The latter specimen was examined by metallography and excessive contamination was observed at one end of the specimen. The contamination appeared to have originated from the graphite coating sprayed on the cores. All other specimens exhibited normal burst properties, with bursting pressures as high as 5800 psi with deflections up to 35 mils.

In an effort to determine if graphite smeared from the sprayed coatings was the cause of the weak bonds obtained in some of the specimens, it was decided to intentionally smear the Zircaloy-2 mating surfaces of the components in two large specimens. The smearing was accomplished during assembly by rubbing gloves over the cores lightly and then over the surrounding surfaces of the Zircaloy- 2 components. These specimens were then processed in the normal manner and burst tested. The as-bonded specimens behaved during burst testing in a manner similar to the as-bonded specimens that had previously exhibited intercompartmental leakage. The beta-treated sections burst at normal burst values with deflections equivalent to those obtained on routine 
$\mathrm{M}-3$

specimens. The results obtained with these specimens are strong evidence that uninten ional graphite smearing of the Zircaloy- 2 components during assembly is the cause of the weak bonds obtained in the as-bonded specimens that failed during burst testing. Four specimens were made using graphite-coated cores that were buffed to an extremely high justre prior to as sembly in order to remove loosely adherent graphite. Twelve compartments in these specimens have been burst tested, and no intercompartmental leakage has developed during the burst testing. This also suggests that smearing of grapl:ite has been the cause of work bonds.

Metallographic examination of a number of the elements prepared revealed the pres $\epsilon$ nce of considerable amounts of bond-line contamination which has prevented complete grain growth from occurring. This contamination is not continuous in nature and varies in degree from one part of an element to another. In addition to the contamiration, a single layer of alpha grains generally one grain wide along each side of the bond interface has been seen in most of the beta-treated specimens. The most probable explanation for these alpha grains is that they are areas of oxygen-rich Zircaloy- 2 caused by outgassing from the coated cores or result from a core-cladding reaction. Further metallographic, X-ray diffraction, and electron-microscopy examinations are being conducted in an effort to determine the nature of the contamination.

The reaction between core and cladding has been minimized by graphite coatings of greater than $3 \mathrm{mg}$ per in. ${ }^{2}$. Two specimens which contained controlled coating densities of from 1 to $9 \mathrm{mg}$ per in. ${ }^{2}$ showed that for densities up to $3 \mathrm{mg}$ per in. ${ }^{2}$ reaction was quite heavy, especially in the beta-treated specimens. For coating densities greater than $3 \mathrm{mg}$ per in. ${ }^{2}$, very little reacticin was observed and no noticeable improvement was obtained with coating densities higher than $5 \mathrm{mg}$ per in. ${ }^{2}$. It has been noted, however, that a series of specimens bonded with cores having coating densities of 5 to $6 \mathrm{mg}$ per in. ${ }^{2}$ showed a higher incidence of intercompartmental leaks during burst testing than those with cores coated to a density of $3 \mathrm{mg}$ per in. ${ }^{2}$ or less. More graphite may be dusted off from the higher density coating, which might account for the observed bond-line contamination.

The effect of thermal cycling on pressure-bonded PWR-type fuel plates is being studied. Sections from an as-bonded specimen and a beta-treated specimen were subjected to a thermal-cycling schedule of heating to $1100 \mathrm{~F}$, annealing $15 \mathrm{~min}$, and cooling to room temperature. This cycle was repeated for 100 cycles. Examination of these specimens revealed no dimensional changes, distortion, or apparent increase in co:e-cladding reaction.

In addition to the large-scale specimens, twelve irradiation-test specimens have been prepared by the pressure-bonding technique. 'Four of these specimens were preparec with one-piece frames, while the remaining eight were prepared from piece componerts. Eight of the 12 specimens were shipped in the as-bonded condition, while the remaining 4 were subjected to a beta treatment prior to shipment for irradiation testing. Half of these specimens were prepared from normal Zircaloy- 2 while the remaining half viere prepared from nickel-free iron-replaced Zircaloy-2. The initial four specimens are scheduled for the X-3-L irradiation testing program and the remaining eight specimens are for KAPL- 120 irradiation tests. 


$$
\text { M-4 }
$$

Additional test data are being collected on all of the specimens bonded to determine the cause for the weak bonds encountered in a portion of the specimens prepared. Test data collected thus far indicate that

(1) Specimens with ductile claddings can be consistently produced.

(2) Piece components can be used in place of a punched Zircaloy-2 frame.

(3) Specimens with no intercompartmental leaks in corrosion have consistently been produced.

(4) Specimens of the large-scale size can be bonded with good dimensional control.

(5) The beta treatment improves the statistical average of the number of specimens that do not exhibit intercompartmental leakage in burst tests at pressures in excess of 2000 psi.

(6) The bonding equipment can consistently be depended upon to have a uniform hot zone.

(7) The final closure of the specimen for bonding can be accomplished by induction welding while evacuating the pack.

(8) As-bonded specimens with properly coated cores may be acceptable.

(9) Beta-treated specimens burst at higher pressures with more deflection than as-bonded specimens.

In addition, tests have revealed that core-cladding reaction has not been completely eliminated with increased coatings of graphite. Some evidence of weak bonds in the form of contaminated bonds or bonds containing a layer of an oxygen-rich alpha phase along the bond line of the beta-treated specimens have been observed. 
$\mathrm{N}-1$.

\title{
N. DEVELOPMENTS FOR THE MGCR
}

\author{
W. H. Goldthwaite
}

In research assistance to the Maritime Gas-Cooled Reactor Program the postirradiation examination of two stainless steel-clad $\mathrm{UO}_{2}$ specimens is essentially concluded. A program which includes the development of fabrication techniques and the irradiation of three potential fuel materials is under way. An investigation of the effects of raliation on the transport of carbon by impurities in helium coolant gas has been initiated.

THE POSTIRRADIATION EXAMINATION OF GA-BNL SINTERED UO 2 FUEL SPECIMENS CLAD WITH STAINLESS STEEL

\author{
G. E. Lamale, D. M. Cheney, A. A. Bauer, \\ and J. E. Gates
}

One of the irradiated samples obtained from Brookhaven National Laboratory contained two pellets of $\mathrm{UO}_{2}$ sintered to a density of 93 per cent of theoretical and clad with $10 \mathrm{mj} 1 \mathrm{~s}$ of Type 316 stainless steel. This sample was irradiated in a $\mathrm{CO}_{2}$ atmosphere to an integrated neutron exposure of $5.2 \times 1018 \mathrm{nvt}$ at a temperature of $1600 \mathrm{~F}$. The cladding on this sample had burst. The second sample contained two pellets of $\mathrm{UO}_{2}$ sinte:ed to a density of 93 per cent of theoretical and clad with 5 mils of Type 316 stainless isteel. This sample was irradiated in a helium atmosphere to an exposure of $4.7 \times 10^{19} \mathrm{nvt}$ at a temperature of $1200 \mathrm{~F}$. This sample did not fail.

Metallographic examination of one of the pellets from the specimen with the $10-\mathrm{mil}$ cladding showed that the center line of the UO? pellet melted during irradiation. The usual equiaxed fine-grained structure was observed at the surface of the specimen. In the $n \in: x t$ deeper zone the grain structure was columnar with a central void, indicating center melting. Melting was also observed at the end which was in contact with the second pellet. A section of the bulged cladding from this specimen was examined at the surface of the break. Large, slate-gray inclusions, presumed to be oxides of iron and nickelt, were visible at the grain boundaries and in the grains. The cladding of this region of the break was essentially porous.

The specimens of $\mathrm{UO}_{2}$ in the sample with the 5 -mil cladding were metallographically quite similar to unirradiated $\mathrm{UO}_{2}$ specimens with small equiaxed grains. A large amount of random transverse cracking was observed, but this could have been caused during handling. There was no evidence of damage caused by fission gas. The examination of the cladding on this sample has not been completed, but it appears to be typical of unirradiated Type 316 stainless steel.

Burnup wafers were taken from both capsules. Both wafers were relatively large, weighing between 4.5 and $6.0 \mathrm{~g}$. Dissolution has been completed and the radiochemical resul:s will be available soon. 
$\mathrm{N}-2$

\section{FABRICATION AND IRRADIATION OF FUEL MATERIALS}

An investigation of potential fuel materials for the MGCR is under way. Procedures for the fabrication of $\mathrm{BeO}_{-} \mathrm{UO}_{2}$, graphite-UC, and graphite- $\mathrm{UC}_{2}$ fuel specimens clad with Type 316 stainless are being developed. The elements will contain approximately 20 volume per cent of 30 per cent enriched fuel. Specimens 1/4 in. in diameter are to be irradiated to burnups of 6,12 , and 20 per cent of the contained uranium-235 at a heat flux of about $200,000 \mathrm{Btu} /(\mathrm{hr})\left(\mathrm{ft}^{2}\right)$ and a surface temperature of $1500 \mathrm{~F}$.

\section{Fabrication of $\mathrm{BeO}-\mathrm{UO}_{2}$ Fuel Elements}

A. K. Smalley, W. C. Riley, and W. H. Duckworth

Experiments leading to the development of a $\mathrm{BeO}-20$ volume per cent $\mathrm{UO}_{2}$ fuel element are in progress. The element will consist of $150-\mu \mathrm{UO}_{2}$ particles uniformly dispersed in a fine-grained densely sintered $\mathrm{BeO}$ matrix.

In previous work, unsintered wax-bonded $\mathrm{UO}_{2}$ particles exhibited considerable dusting on mixing with $\mathrm{BeO}$. Also, various dry-mixing methods were unsatisfactory for obtaining a uniform dispersion of $\mathrm{UO}_{2}$ grains in $\mathrm{BeO}$ powder.

The fabrication method was modified to combat these difficulties. Uniform mixtures in which the matrix contained a minimum of $\mathrm{UO}_{2}$ dust were prepared by the following method:

(1) $\mathrm{UO}_{2}$ grains were sintered at $2800 \mathrm{~F}$ prior to incorporating them into the $\mathrm{BeO}$. The sintered grains were then sized by screening to the range of 105 to $150 \mu$.

(2) Brush Beryllium Company LOH-grade $\mathrm{BeO}$ was treated with $3 \mathrm{w} / \mathrm{o}$ of Carbowax 4000 . It then was made into a heavy paste with a wateracetone mixture. The paste was placed in a Stewart-Bolling roll mixer, and the sintered $\mathrm{UO}_{2}$ grains were sifted into the $\mathrm{BeO}$ while mixing. Mixing was continued until the batch had reached a leatherhard consistency.

(3) The flakes from the roll mixer were granulated while still moist and screened through an 18-mesh sieve. The mixture was dried and compacted isostatically in rubber molds at 50,000 psi. Compacts were sintered for $1 \mathrm{hr}$ at $2800 \mathrm{~F}$ in flowing hydrogen.

Specimens of $\mathrm{BeO}-20$ volume per cent $\mathrm{UO}_{2}$ containing enriched fuel are being prepared for encapsulation and irradiation. 
$\mathrm{N}-3$

Fabrication of Graphite Fuel Elements

W. A. Hedden, A. B. Tripler, Jr., A. J. Roese, W. C. Riley, and W. H. Duckworth

The objective of this research is to develop techniques for fabrication of graphitematrix fuel cores containing 20 volume per cent uranium carbide in the form of UC and $\mathrm{UC}_{2}$

It was reported last month that test specimens had been prepared containing 20 vislume per cent of natural $\mathrm{UO}_{2}, \mathrm{UC}$, and $\mathrm{UC}_{2}$. These specimens contained either petroleum coke or graphite filler and were bonded with either coal-tar pitch or phenolformaldehyde resin. Specimens of each type were baked at $2000 \mathrm{~F}$ in a protective atmosphere of argon gas.

During this report period, the bodies containing $\mathrm{UO}_{2}$ were heated further at $4600 \mathrm{~F}$ to convert the $\mathrm{UO}_{2}$ to $\mathrm{UC}_{2}$. Appreciable disintegration occurred during the final heat treatment. The weakening of the carbon structure in these specimens probably resulted from oxidation of the graphite during conversion of the relatively large amount of $\mathrm{U}_{2}$ to $\mathrm{UC}_{2}$.

$\mathrm{X}$-ray diffraction and metallographic studies indicated a slight oxidation of the $\mathrm{UC}$ and $\mathrm{UC}_{2}$ particles occurred during procesising in the bodies that were bonded with phenolformaldehyde resin and baked at $2000 \mathrm{~F}$. In the bodies that were bonded with coal..tar pitch and baked at $2000 \mathrm{~F}$, no measurable oxidation occurred during processing. Also, the pitch-bonded bodies were more firm and dense than those bonded with phenolformaldehyde resin. The optimum pitch content appeared to be about 15 parts by weight per 100 parts of total solids in the baked body. Bodies of this type will be fabricaled with enriched fuel for irradiation testing. Dimensions will be approximately $1 / 4 \mathrm{in}$. in length and $0.222 \mathrm{in}$. in diameter.

\section{Radiation-Effects Study of Potential Fuels}

J. E. Gates, C. V. Weaver, J. H. Stang, and R. F. Dickerson

A fuel system is being developed for the MGCR which will operate in an environmen1. such that fuel-element-surface temperatures as high as $1500 \mathrm{~F}$ may be attained. This high temperature coupled with a surface-heat flux as high as $150,000 \mathrm{Btu} /(\mathrm{hr})\left(\mathrm{ft}^{2}\right)$ and $:$ minimum fuel-pin diameter of $0.25 \mathrm{in}$. restricts the choice of a fuel to a ceramic or cermet-type material. Since undiluted $\mathrm{UC}_{2}$ is not acceptable because of the high absorption cross section of uranium-238 in the anticipated epithermal flux, uranium compounds dispersed in graphite or $\mathrm{BeO}$ are being considered. It will be necessary, however, to observe the effects of radiation on these experimental fuels as close to desiøn conditions as possible. Such effects as fission-gas release, swelling, or decrepitation, any of which would cause failuse of the element, would be observed. 
$\mathrm{N}-4$

It is planned to irradiate pellets of $\mathrm{BeO}$ fueled with $\mathrm{UO}_{2}$, pellets of graphite fueled with $\mathrm{UC}_{2}$, and pellets of graphite fueled with UC. The density of the BeO and graphite pellets will be about 95 and 77 per cent of theoretical, respectively. The BeO-matrix fuel specimens will contain about 20 volume per cent of 30 per cent enriched $\mathrm{UO}_{2}$. The uranium-235 content of the graphite specimens will be adjusted to match the content of the BeO. Present plans call for four pellets of the same material, each about $0.222 \mathrm{in}$. in diameter by $0.25 \mathrm{in}$. long, to be loaded into Type 316 stainless steel tubes under helium. The tubes will be 0.250 in. in diameter with a wall thickness of $0.012 \mathrm{in.}$, leaving a diametral gap of $0.004 \mathrm{in}$. between the pellets and tube. Small cylindrical spacers of $\mathrm{Al}_{2} \mathrm{O}_{3}$ will be used to prevent the pellets from touching the bottom of the tube. Calculations have indicated that the over-all length of the specimens will have to be about 1.5 in. to allow expansion space for fis'sion gas, if large amounts are released. Six specimens, two of each of the three fuel materials, will be loaded in each of four capsules. Thermocouples and heaters will be incorporated in each capsule to permit measurement and to some degree control the specimen temperatures.

The irradiations are to be conducted in the MTR to burnups of 6,12 , and 20 per cent of the uranium-235 at specimen surface temperatures of $1500 \mathrm{~F}$ and surface heat fluxes of $200,000 \mathrm{Btu} /(\mathrm{hr})\left(\mathrm{ft}^{2}\right)$. If necessary, one capsule may be irradiated in the $B R R$ in order to complete the specimen examination by June 30, 1959.

Preparation of the fueled pellets and specimen tubes has been initiated. Final capsule designs are being completed. A target date of February 12 has been selected for completion of sufficient specimens for the first capsule. The capsule must be loaded and shipped to the MTR by February 19 in order to have the irradiation start by March 16, the beginning of MTR Cycle 119. If the latter date cannot be met for any reason, the capsule will be irradiated in the BRR.

\section{CORE-MATERIALS IRRADIATION PROGRAM}

C. V. Weaver, N. E. Miller, and W. S. Diethorn

As part of the core-materials evaluation program for the MGCR, a study of the effect of reactor radiation on graphite and metals in helium has been initiated at Battelle.

Small amounts of hydrogen, oxygen, $\mathrm{CO}, \mathrm{CO}_{2}, \mathrm{CH}_{4}$, and water impurities present in the initial charge of this candidate coolant, and amounts released from the unclad graphite moderator during reactor operation, may attack the moderator and core metals. The purpose of the study is to investigate carbon transport and corrosion when degassed graphite and metals are irradiated together in closed quartz capsules filled with $1 \mathrm{~atm}$ of commercial helium.

Four capsules of identical design will be irradiated in the BRR for a period of $1000 \mathrm{hr}$. Two of the capsules will contain zirconium getter in addition to the graphite and metal specimens. The capsule design is best described as a thermal-convection harp. The capsule is cylindrical and divided into two compartments by a heat barrier 


\section{$\mathrm{N}-5$ and $\mathrm{N}-6$}

runing almost the full length of the long axis of the capsule. There are separate heaiers on the outside of the capsule shell to maintain a temperature of $1500 \mathrm{~F}$ in one corpartment and $800 \mathrm{~F}$ in the other. Helium is permitted to circulate by convection arolnd the loop defined by the barrier and the capsule shell, and over the graphite and metal specimens in each compartment.

The postirradiation study will include metallographic examination and measuremert of weight changes of the specimens, and mass-spectrometric analysis of the impurity levels in the helium.

Capsule design and construction is under way in preparation for reactor insertion in Mlarch. 


$$
\mathrm{O}-1 \text { and } \mathrm{O}-2
$$

\section{O. ENGINEERING ASSIST ANCE TO KAISER ENGINEERS}

\section{Reactor Flow Studies}

L. J. Flanigan and H. R. Hazard

Studies of flow in a quarter-scale air-flow model of the Partially Enriched GasCoo.ed Power Reactor are being conducted to provide design data for the prototype. Prerious work included completion of the detailed design, evaluation of bids for manufacture of the plastic model parts, and initiation of construction of the model core at Battelle.

In January, selection of a fabrication of the plastic parts was made, and the fabricator has started to make the parts. Construction of the model core was continued and Eabrication of parts for the test facility was started.

In February, fabrication of the plastic parts and the parts for the test facility will continue. Assembly of the model core will begin. 
$P-1$

\title{
P. DEVELOPMENTAL STUDIES FOR THE APPR
}

\author{
S. J. Paprocki
}

The objective of this program of assistance to Alco Products in the development of the A.PPR Core $1 B$ is to establish specifications for the fuel, absorber, and suppressor materials. This involves development of fabrication processes, determination of physical and mechanical properties, and irradiation testing.

Core lB will contain boron as a burnable poison. Several methods for incorporating the boron into the core are being investigated. A dispersion of a compatible boron compound in the fuel core has been chosen as the reference method. By control of the: sintering atmosphere, it has been possible to sinter cores of Type 347 stainless containing $\mathrm{NbB}_{2}, \mathrm{CrB}_{2}$, and $\mathrm{ZrB}_{2}$ at $2300 \mathrm{~F}$ without apparent reaction.

Capsules are being designed for the irradiation testing of promising fuel materials. The c.verage burnup of the proposed Core IB fuel is 38 per cent and the peak burnup is 77 per cent of the contained uranium-235. In order to obtain the peak burnup in the time required to establish material specification, it will be necessary to irradiate the specimens in an unperturbed flux of 3 by $10^{14} \mathrm{nv}$. Calculations indicate that a severe heattransfer problem exists because the heat-generation rate at the start of irradiation will be about 10,000 Btu per hr per in. of specimen.

\section{Encapsulation Studies}

W. E. Murr, A. K. Hopkins, D. B. Hamilton, and J. H. Stang

Studies are in progress on the design of capsules for the irradiation of fueled specinens of interest to the APPR Core 1B materials development program. Specimens will consist of dispersions of fully enriched $\mathrm{UO}_{2}$ in stainless steel. Desired irradiation conditions include (1) a nominal specimen surface temperature of $650 \mathrm{~F}$, and (2) fission burnup to an average of 38-1/2 per cent and to a maximum of 77 per cent of the ur anium-235. Approximately five average-burnup and five high-burnup capsules are sheduled, with each capsule containing six specimens. Each capsule will be equipled with auxiliary heaters and thermocouples.

Emphasis during January was placed on appraising various aspects of the capsule heat-1 ransfer situation, particularly for the high-burnup systems. To conform with the over-all schedule, all irradiations must be completed within a period of about 1 year with May 1, 1959, as a reference starting date. To meet such a schedule, nuclear calculations indicate that the high-burnup capsules must be irradiated in a reactor space where the unperturbed flux is about $3 \times 10^{14} \mathrm{nv}$. Under these conditions, the heatgeneration rate at the start of irradiation will be very high (about 10,000 Btu per hr per in. of specimen) and will demand that the capsule systems have very high heatdissipation characteristics. For example, recent analog simulation studies made of various capsule cross sections handling the equivalent of 10,000 Btu per in. demonstrate 


$$
\mathrm{P}-2
$$

that immersion of $1 / 2$ by $1-i n$. specimens in sodium contained in a stainless steel shell directly contacting the pool water will not provide a thermal conductance adequate to suppress the specimen temperature to $650 \mathrm{~F}$. With such a design, specimen temperature at the start of irradiation would be approximately $900 \mathrm{~F}$, even in a flux of $2-1 / 2 \mathrm{x}$ $10^{14} \mathrm{nv}$. However, the sodium-stainless steel combination will probably be adequate for the low-burnup capsules, since the heat-generation rates will be relatively low.

In view of the high-burnup-capsule situation, attention is being turned to substituting a very-high-conductivity material, such as aluminum or copper for a fraction of the sodium. Another possibility is to incorporate some burnable poison in the capsule to lower the effective flux during the early stages of the experiment. While reasonable from the heat-transfer viewpoint, such schemes will introduce formidable capsuleconstruction problems. If these are not resolvable, it will be necessary to reduce the fuel content of the specimens or accept a lower flux irradiation, and consequently, a lower burnup rate.

The inner capsule space is very limited because much of it will be occupied by auxiliary heaters; the heaters present must have the capacity to maintain specimen temperature during a large part of the irradiation. It now appears possible to provide enough heaters to maintain the reference temperature until a burnup of approximately 60 per cent has been reached.

Negotiations are now being conducted with MTR/ETR personnel for high-flux ir radiation space. It is recognized that the availability of positions having the desired flux is limited and that this will be an important governing factor in scheduling the ir radiation tests.

\section{Development of Fuel Materials}

S. J. Paprocki, D. L. Keller, G. W. Cunningham, J. B. Fox, D. E. Lozier, and W. M. Pardue

Three methods are being investigated for incorporating a boron burnable poison in the APPR Core IB: (1) dispersion of a boron compound in the fuel-element core, (2) use of a discrete burnable poison component, and (3) use of a stainless-boron alloy as an integral part of the fuel-element subassembly. The dispersion of a compatible boron compound in the fuel core has been chosen as the reference method for incorporating boron into the core. The other two methods are being considered as alternates.

A number of bor on compounds have been tested to determine compatibility with Type 347 stainless steel. They include $\mathrm{CrB}, \mathrm{CrB}_{2}, \mathrm{NbB}_{2}, \mathrm{FeB}, \mathrm{Fe}_{2} \mathrm{~B}, \mathrm{MoB}$, NiB, $\mathrm{Ni}_{2} \mathrm{~B}, \mathrm{SiB}_{3}, \mathrm{ZrB}_{2}, \mathrm{CaB}_{6}$, and $\mathrm{YB}_{6}$. Some of the compounds, such as $\mathrm{NiB}$, were known to react with stainless, but were included to gain information on the boron-stainles $s$ reaction. The compounds $\mathrm{CrB}_{2}, \mathrm{NbB}_{2}, \mathrm{MoB}, \mathrm{ZrB}_{2}, \mathrm{CaB}_{6}$, and $\mathrm{YB}_{6}$ are being investigated. Since high-purity $\mathrm{CaB}_{6}$ and $\mathrm{YB}_{6}$ are not available commercially, the se compounds are being prepared in the laboratory and no compatibility data have been obtained. 
$\mathrm{P}-3$

Specimens containing $\mathrm{NbB}_{2}, \mathrm{CrB}_{2}$, and $\mathrm{ZrB}$ have been prepared which show little or no reaction with the Type 347 stainless matrix.

Since $\mathrm{NbB}_{2}$ and $\mathrm{CrB}_{2}$ and in particular $\mathrm{ZrB} 2$ oxidize readily, it appears that both the cixygen content of the metal powders and the purity of the sintering atmosphere are impcrtant in determining the compatibility of the boron compound. For example, specimen:s containing $1 \mathrm{w} / 0$ boron in the form of $\mathrm{NbB}_{2}$ or $\mathrm{CrB}_{2}$ dispersed in prealloyed Type 347 stainless and sintered $3 \mathrm{hr}$ in vacuo at $2300 \mathrm{~F}$ did not show any evidence of reaction, while similar specimens sintered $3 \mathrm{hr}$ in hydrogen with a $-35 \mathrm{~F}$ dewpoint showed gross reaction and distortion of the compacts. Similar results were obtained wher: specimens were sintered at $2100 \mathrm{~F}$.

On the other hand' modifications of the hydrogen sintering treatment or combinatic ns of hydrogen and vacuum sintering appear promising. Dispersions of $\mathrm{CrB}_{2}$ in elerental Type 347 matrices did not show reaction upon metallographic examination after sintering under the following conditions: (1) sinter $4 \mathrm{hr}$ in hydrogen at $1600 \mathrm{~F}$, heat to $1800 \mathrm{~F}$ and hold for $7 \mathrm{hr}$ in hydrogen, cool, heat to $2300 \mathrm{~F}$ in vacuo and hold for $\bar{z} \mathrm{hr}$; (2) hold $7 \mathrm{hr}$ at $1800 \mathrm{~F}$ in vacuo, hea.t to $2300 \mathrm{~F}$ and hold for $2 \mathrm{hr}$ in vacuo; (3) sinter $4 \mathrm{hr}$ at $1600 \mathrm{~F}$ in hydrogen, heat to $1800 \mathrm{~F}$ and hold $7 \mathrm{hr}$ in hydrogen, heat to $2300 \mathrm{~F}$ and hold $2 \mathrm{hr}$ in hydrogen. Similar specimens containing $\mathrm{NbB}_{2}$ did not show reaction except when subjected to Treatment (3).

The oxidation of $\mathrm{ZrB}_{2}$ is more difficult to prevent. However, reaction generally seems to be confined to the $\mathrm{ZrB}_{2}$ particles ard there does not appear to be a reaction of boron with the matrix. Any of the sintering procedures listed above which reduced the amount of oxygen contamination also reduced the $\mathrm{ZrB}_{2}$ reaction.

Additional information on the effect of oxygen contamination will be obtained from tests now in progress in which the boride powders are being heat treated in $-90 \mathrm{~F}$ hydrogen. The powders will be measured for weight gain or loss and analyzed for change in comfosition and phase. Also, specimens being evaluated at the present time indicate that $a$ hydrogen-sintering technique for holding $16 \mathrm{hr}$ at $1600 \mathrm{~F}$ and heating at a rate $170 \mathrm{Jr}$ per hr to $2250 \mathrm{~F}$ and holding for $2 \mathrm{hr}$ may be satisfactory for sintering specimens with prealloyed stainless matrices.

Fabrication procedures for roll cladding green fuel element cores are being investigatıd. Green compacts containing $28 \mathrm{w} / \mathrm{o} \mathrm{UO}_{2}$ or an equivalent loading of UN (24 w/o) and $1 \mathrm{w} / 0$ boron incorporated as $\mathrm{NbB}_{2}, \mathrm{CrB}_{2}, \mathrm{MoB}$, or $\mathrm{ZrB}_{2}$ in a prealloyed Type 347 stainless matrix have been roll clad at $2000 \mathrm{~F}$ using a 10 -to-1 reduction in thickness. Littl 3 or no reaction occurred in all cases when $\mathrm{NbB}_{2}$ was used. No reaction occurred when $\mathrm{ZrB}_{2}$ was used in the elements containing $\mathrm{UN}$. Little or no reaction between $\mathrm{CrB}_{2}$ and the matrix could be detected, but voids were visible in the center of the $\mathrm{CrB}_{2}$ particle:s. It has not been established whether these voids occur during fabrication or are presınt before use. No reaction was detected when MoB was used.

Although results reported to date indicate that fabrication procedures can be developed to incorporate boron in the fuel element as $\mathrm{NbB}_{2}, \mathrm{CrB}_{2}$, or $\mathrm{ZrB}_{2}$, no reference 
boride has been chosen. Based on X-ray diffraction results, commercially produced $\mathrm{NbB}_{2}$ and $\mathrm{CrB}_{2}$ are not pure diborides but are actually mixtures of two niobium or chromium borides. Consequently, there may be difficulty in determining the exact amount of boron contained in the fuel element. Also, voids noted in $\mathrm{CrB}_{2}$ may be due to small amounts of boron diffusing into the matrix and, if such diffusion is occurring, chemical analytical methods will have to be developed for detecting the amount of diffusion. Specimens containing large boride particles are being prepared for study. In. addition, complete information on boron loss during sintering has not been obtained. Sintering studies indicate that the only loss is probably due to oxidation and consequent vaporization of $\mathrm{B}_{2} \mathrm{O}_{3}$. This loss may be greater for $\mathrm{ZrB}_{2}$ than $\mathrm{NbB}_{2}$ or $\mathrm{Cr} \mathrm{B}_{2}$. Stoichiometric $\mathrm{YB}_{6}$ and $\mathrm{CaB}_{6}$ are also being prepared and compatibility tests will be run.

The preferred method of including the poison is as a dispersion in the fuel core. The feasibility of introducing the poison by other methods is being considered. Calculations indicate that a $100-$ mil-OD stainless steel tube spaced in each channel loaded with the required amount of burnable poison could contain the helium gas release. The poison could possibly be introduced into the tubes as a powder, by vapor deposition on the inside of the tube, or as a high-percentage boron-10 wire. Calculations indicate the feasibility of introducing the poison as a bare Type 347 stainless steel-0. 2 w/o boron-10 alloy wire in each channel. The stainless-boron alloy can also be used as the structural component of the fuel assemblies.

RWD:CRT/a11 